\title{
Patterns of Nogo mRNA and Protein Expression in the Developing and Adult Rat and After CNS Lesions
}

\author{
Andrea B. Huber, Oliver Weinmann, Christian Brösamle, Thomas Oertle, and Martin E. Schwab \\ Brain Research Institute, University of Zurich, Zurich, 8057 Switzerland, and Department of Biology, Swiss Federal \\ Institute of Technology, Zurich, 8057 Switzerland
}

\begin{abstract}
Nogo-A is a neurite growth inhibitor involved in regenerative failure and restriction of structural plasticity in the adult CNS. Three major protein products (Nogo-A, -B, and -C) are derived from the nogo gene. Here we describe the embryonic and postnatal expression of the three Nogo isoforms in the rat by in situ hybridization and immunohistochemistry. Northern and Western blot analysis indicated that Nogo-A is predominantly expressed in the nervous system with lower levels also present in testis and heart. In CNS myelin, confocal and immunoelectron microscopy revealed that Nogo-A is expressed in oligodendrocyte cell bodies and processes and localized in the innermost adaxonal and outermost myelin membranes. Additionally, we find Nogo-A to be expressed by projection neurons, in particular during development, and by postmitotic cells in the developing cortex, spinal cord, and cerebellum. The expression
\end{abstract}

levels of Nogo-A/B were not changed significantly after traumatic lesions to the cortex or spinal cord. Nogo-B showed widespread expression in the central and peripheral nervous systems and other peripheral tissues. Nogo-C was mainly found in skeletal muscle, but brain and heart were also found to express this isoform. The localization of Nogo-A in oligodendrocytes fits well with its role as a myelin-associated inhibitor of regenerative fiber growth and structural plasticity. However, expression of Nogo-A in other tissues and, in particular, in neurons and the widespread expression of the two shorter isoforms, Nogo-B and $-C$, suggest that the Nogo family of proteins might have function(s) additional to the neurite growthinhibitory activity.

Key words: oligodendrocyte; myelin; neurite growth inhibition; development; spinal cord injury; regeneration
Regrowth of injured axons in the adult CNS of higher vertebrates is very restricted. Myelin-associated neurite growth inhibitors are at least in part responsible for this lack of regeneration (Schwab and Bartholdi, 1996; Olson, 1997). A monoclonal antibody $(\mathrm{mAb}), \mathrm{IN}-1$, raised against a major myelin-associated neurite growth inhibitor, called NI-250, was able to neutralize the growth-inhibiting activities of the substrate to the extent that neurons in culture could send out neurites on a CNS myelin substrate or on CNS white matter (Caroni and Schwab, 1988). Similarly, neurite outgrowth over differentiated oligodendrocytes in culture and into optic nerve explants was strongly facilitated after neutralization of the inhibitory substrates by mAb IN-1 (Caroni et al., 1988; Savio and Schwab, 1989). Using such bioassays, the bovine homolog bNI220 was purified and partially sequenced (Spillmann et al., 1998). Recently, we and others cloned the cDNA of this myelin-associated neurite growth inhibitor and mAb IN-1 antigen and called the gene nogo- $A$ (Chen et al., 2000; GrandPré et al., 2000; Prinjha et al., 2000). Northern blot analysis revealed three major transcripts, which have been called nogo- $A,-B$, and $-C$, generated by both alternative splicing and promotor use. Anti-Nogo-A antisera (AS) Bruna and AS 472 were able to neutralize the neurite growth-inhibitory activity of

Received Sept. 25, 2000; revised Jan. 31, 2002; accepted Feb. 5, 2002.

This study was supported by Swiss National Science Foundation Grant 3145549.95, the Christopher Reeve Paralysis Foundation (Springfield, NJ), and the Biotechnology Program of the European Union (Brussels, Belgium). We thank F. Christ and T. Flego for technical assistance and R. Schöb for help with the figures.

Correspondence should be addressed to Andrea B. Huber, Department of Neuroscience, The Johns Hopkins School of Medicine, 725 North Wolfe Street, Baltimore, MD 21205. E-mail: ahuber@jhmi.edu.

Dr. Brösamle's present address: Department of Embryology, Carnegie Institution of Washington, 115 West University Parkway, Baltimore, MD 21210.

Copyright (C) 2002 Society for Neuroscience $0270-6474 / 02 / 223553-15 \$ 15.00 / 0$ cultured live oligodendrocytes and central myelin (Chen et al., 2000). All three Nogo isoforms share a common C-terminal domain of 188 amino acids (aa) with two long hydrophobic stretches (35 and 36 aa) that could serve as potential transmembrane domains. Nogo-A was further shown to be expressed by oligodendrocytes in myelinated tissues of the CNS.

In vivo experiments demonstrated the important role played by this myelin-associated protein in inhibiting axonal regeneration after injury. After mAb IN-1 or recombinant IN-1 Fab' application in a rat model of spinal cord injury, long-distance regeneration of the severed corticospinal tract axons was observed after survival times of a few weeks (Schnell and Schwab, 1990; Bregman et al., 1995; Brösamle et al., 2000). In addition to the regenerative growth of lesioned fibers observed after IN-1 application, unlesioned fiber tracts also reacted to the neutralization of myelin-associated growth inhibitors. Sprouting of intact fiber systems was observed after a unilateral lesion of the corticospinal tract (CST) at the pyramidal decussation; in the spinal cord the remaining intact CST was found to send out collaterals across the midline and to innervate the denervated side of the adult rat spinal cord (Thallmair et al., 1998). Sprouting also occurred in the brainstem and was accompanied by a high level of functional recovery of precision movements (Z'Graggen et al., 1998). mAb IN-1 immunoreactivity was found earlier to be present mainly in CNS myelin (Rubin et al., 1994). However, only now with the molecular characterization of Nogo and new reagents available, a thorough analysis of the expression pattern of the Nogo isoforms has become feasible.

Here we present an expression analysis of the three Nogo isoforms during development and in the adult rat using in situ hybridization and immunohistochemistry. We find Nogo-A to be 
expressed in myelin of the mature CNS but also in neurons, especially during development. We investigated the expression pattern of Nogo-A/B after cortical and spinal lesions at several time points and found no significant changes of expression in oligodendrocytes after injury. Nogo-B showed widespread expression in CNS as well as in peripheral tissues, and Nogo-C was found to be strongly expressed in skeletal muscle and to lower levels also in brain and heart. This raises the possibility that besides the neurite growth-inhibitory function, the Nogo family of proteins might have additional, so far unknown physiological roles.

\section{MATERIALS AND METHODS}

Animals and tissues. Tissues of embryonic and postnatal Lewis rats were used in this study. The day of vaginal plug detection was considered embryonic day 1 (E1). Pregnant females were decapitated, and the embryos (E14, E16, and E19) were rapidly removed, embedded in Tissue Tek (OCT compound; Zoeterwoude), and frozen in isopentane at $-40^{\circ} \mathrm{C}$ for subsequent in situ hybridization and immunohistochemistry. Brain, spinal cord, and eyes of postnatal animals from postnatal day 0 (P0), P1, P3, P5, P9, P14, and adult animals were removed and processed as indicated above. Each developmental time point was analyzed in at least three different animals. In addition, tissues from adult decapitated animals were collected for Western and Northern blotting. For confocal microscopy, adult Lewis rats were killed with pentobarbital $(500 \mathrm{mg} / \mathrm{kg})$ and perfused transcardially with Ringer's solution followed by $4 \%$ paraformaldehyde in $0.15 \mathrm{M}$ phosphate buffer with $5 \%$ sucrose. The spinal cords were removed and post-fixed overnight in $4 \%$ paraformaldehyde and phosphate buffer.

CNS lesions. Animal experimental procedures were approved by the Veterinäramt of the Canton of Zurich. Animals were deeply anesthetized by intraperitoneal injection of fentanyl citrate $(0.0189 \mathrm{mg} / 100 \mathrm{gm}$ body weight), fluanisone (0.6 mg/100 gm, Hypnorm; Janssen Biochimica, Berse, Belgium), and midazolam $(0.6 \mathrm{mg} / 100 \mathrm{gm}$, Dormicum; Hoffmann-La Roche, Basel, Switzerland). For spinal cord lesions, the skin on the back of the animals was opened, and the vertebral column was exposed. A laminectomy was performed at level T8, and the dorsal half of the spinal cord was transected with fine iridectomy scissors. The back muscles were sutured; the skin was closed with surgical staples; and the animals were left to recover on a heating pad. For cerebral cortex lesions, the scalp of the head was incised, and the skull was opened with a dental drill. A longitudinal cut of $\sim 5 \mathrm{~mm}$ was performed in one hemicortex 2 $\mathrm{mm}$ lateral to the midline. The scalp was sutured, and the animals were left to recover on a heating pad. After survival times of 1 and $4 \mathrm{~d}$ and 1 , 2 , and 4 weeks, the animals were killed by decapitation, and the tissue was removed, embedded in Tissue Tek, and frozen at $-40^{\circ} \mathrm{C}$ in isopentane.

Antibodies. AS Bruna was generated against a partial recombinant Nogo-A protein (aa 762-1163); AS Bianca, specific for the N terminus of Nogo-A and -B, was raised against bacterially produced, immobilized metal affinity chromatography-purified and gel-electroeluted fragments aa 1-172 and aa 1-31 and 59-172 of rat Nogo-A; and AS 472 specific for Nogo-A and AS 818 specific for Nogo-C were produced against the synthetic peptides SYDSIKLEPENPPPYEEA (bovine sequence), corresponding to rat sequence aa 623-640 with three mismatches (Chen et al., 2000), and MDGQKKHWKDKVVD (rat sequence), respectively (Research Genetics, Huntsville, AL). As controls, the corresponding preimmune sera and antisera preincubated with the corresponding immunogenic peptides were used. mAb IN-1 was raised against a partially purified CNS myelin fraction (Caroni and Schwab, 1988). Because its binding site on the Nogo protein is probably a conformational epitope, it has not been determined so far. Its usefulness for a detailed differential expression analysis is therefore limited. For immunohistochemistry the

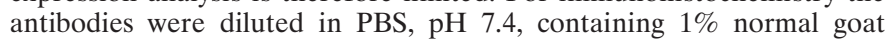
serum as follows: mAb IN-1 hybridoma supernatant, 1:5; AS Bruna, 1:7500; AS Bianca, 1:2000; AS 472, 1:2000; AS 818, 1:2000; affinitypurified AS 818, 1:50; anti-myelin-associated glycoprotein (MAG), 1:25 (Roche); anti-myelin oligodendrocyte glycoprotein (MOG), 1:25 (Roche); anti-neurofilament, 1:100 (Roche); and anti-myelin basic protein (MBP), 1:250 (Roche). For Western blots the following dilutions in 0.1 M Tris buffer, $\mathrm{pH} 8.0$, with $0.1 \%$ Triton X-100 were used: AS Bruna, 1:5000; AS Bianca, 1:5000; AS 472, 1:2000; and affinity-purified AS 818, $1: 100$.
Northern blot analysis. Poly $\left(\mathrm{A}^{+}\right)$RNA was extracted from adult rat tissues using the FastTrack kit (Invitrogen, Groningen, The Netherlands). RNAs were separated by electrophoresis on $1 \%$ formaldehyde gels and transferred to Genescreen membranes (DuPont, Billerica, MA). Blots were hybridized with the common antisense riboprobe as described earlier (Chen et al., 2000). Blot hybridization, washing, and CDP-star detection were done as described by the manufacturer (Roche).

SDS gels and Western blotting. Tissues were homogenized and extracted on ice in $0.1 \mathrm{M}$ Tris buffer, $\mathrm{pH} 8.0$, with $60 \mathrm{~mm}$ 3-[(3-cholamidopropyl) dimethylammonio]-1-propanesulfonic acid, $10 \mathrm{~mm}$ EDTA, $2.5 \mathrm{~mm}$ iodoacetamide, $1 \mathrm{~mm}$ phenylmethylsulfonyl fluoride, $0.1 \mu \mathrm{g} / \mathrm{ml}$ aprotinin, 1 $\mu \mathrm{g} / \mathrm{ml}$ leupeptin, and $1 \mu \mathrm{g} / \mathrm{ml}$ pepstatin A. Tissue debris was pelleted to get a clear supernatant. Twenty-five micrograms of total protein were dissolved in sample buffer, and SDS-PAGE and Western blotting were performed as described (Frank et al., 1998). The secondary antibody was HRP-conjugated anti-rabbit or anti-mouse (1:20,000; Pierce, Rockford, IL) and was visualized using a chemiluminescence system (SuperSignal; Pierce). Tissues from five individual animals were analyzed separately.

In situ hybridization. Digoxygenin-labeled sense and antisense RNA probes were generated as described (Schaeren-Wiemers and GerfinMoser, 1993). The nogo- $A$ probe was synthesized from a 2368 bp rat nogo- $A$-specific template (nucleotides $815-3183$ ); the common probe, recognizing all three isoforms of nogo, contains transcript A sequence between nucleotides 2535 and 4678 (Fig. 1). Cryostat sections $(15 \mu \mathrm{m})$ were collected on Superfrost-Plus slides (Menzel-Gläser, Braunschweig, Germany), and in situ hybridization was performed as described earlier (Schaeren-Wiemers and Gerfin-Moser, 1993). In brief, sections were post-fixed in $4 \%$ paraformaldehyde and PBS, acetylated in $0.1 \mathrm{M}$ triethanolamine and $0.25 \%$ acid anhydride, and permeabilized for either 20 min (postnatal tissues) or 5 min (embryonic tissues) in 1\% Triton X-100 and PBS. Hybridization was performed overnight in $5 \times$ SSC buffer containing $50 \%$ formamide and $2 \%$ blocking reagent (Roche) at $68^{\circ} \mathrm{C}$. Two stringent washes were performed in $0.2 \times \mathrm{SSC}$ at the same temperature for $1 \mathrm{hr}$, and signals were detected with alkaline phosphatasecoupled anti-digoxigenin antibodies (Roche) using nitroblue tetrazolium (NBT) and 5-bromo-4-chloro-3-indolyl phosphate (BCIP) as color reaction substrates.

Immunohistochemistry and histoblot. Myelin proteins, e.g., MBP, are sensitive to fixation and tissue permeabilization. Different fixation methods were used to optimize tissue structure and preservation of the various antigens to match the immunohistochemical signal to the relevant distribution of Nogo as detected by the in situ hybridization and histoblot procedure. Fifteen micrometer serial cryostat sections were mounted on Superfrost-Plus slides and either fixed with ethanol and acetic acid as described earlier (Rubin et al., 1994), except that the quenching step was omitted, or incubated for $30 \mathrm{sec}$ in $-20^{\circ} \mathrm{C}$ methanol or methanol and DMSO $(10 \%)$. For EGTA-ethanol and acetic acid treatment, sections were incubated for $5 \mathrm{~min}$ at $4^{\circ} \mathrm{C}$ in $0.1 \mathrm{M}$ PIPES, $5 \mathrm{~mm}$ EGTA, and $2 \mathrm{~mm}$ $\mathrm{MgCl}_{2}, \mathrm{pH} 6.8$, before ethanol and acetic acid fixation. The primary antibodies were incubated overnight at $4^{\circ} \mathrm{C}$, and subsequent treatment was as described (Rubin et al., 1994). Signal detection was done with biotinylated goat anti-rabbit antibodies (Vector Laboratories, Burlingame, CA) and the ABC kit (Vector Laboratories) using 3,3'diaminobenzidine as a chromogen. Peptide competition of the antibody signal was performed by preincubation of the antibody for $2 \mathrm{hr}$ in the presence of the immunogenic peptide $(0.25 \mu \mathrm{g} / \mu \mathrm{l})$. The sections were evaluated using a Zeiss (Oberkochen, Germany) Axiophot microscope. For confocal laser scanning microscopy, $20 \mu \mathrm{m}$ serial cryostat sections were mounted on Superfrost-Plus slides and pretreated for $20 \mathrm{~min}$ either in ethanol and acetic acid for double staining for MBP and Nogo-A or in Kryofix (Merck, Darmstadt, Germany) for double staining for MAG or MOG and Nogo-A and processed as indicated above. The sections were analyzed using a Zeiss LSM 410 microscope. To confirm the semiquantitative immunohistochemistry signals, we used a modified histoblot method for direct transfer of proteins from a fresh frozen section to an immobilized matrix. Briefly, a nitrocellulose membrane was wetted in SDS-containing transfer buffer (Benke et al., 1995). Twelve micrometer cryostat sections were quickly thawed, pressed onto the membrane for 30 sec, and inspected for complete transfer. The proteins bound to nitrocellulose membranes were immunostained with respective antisera using the procedure of conventional Western blotting. Immunoreactivity was visualized using the alkaline phosphatase reaction substrate system (NBT and BCIP).

Electron microscopic immunohistochemistry. Animals were transcardially perfused by Ringer's solution, followed by $4 \%$ formaldehyde, $0.25 \%$ 

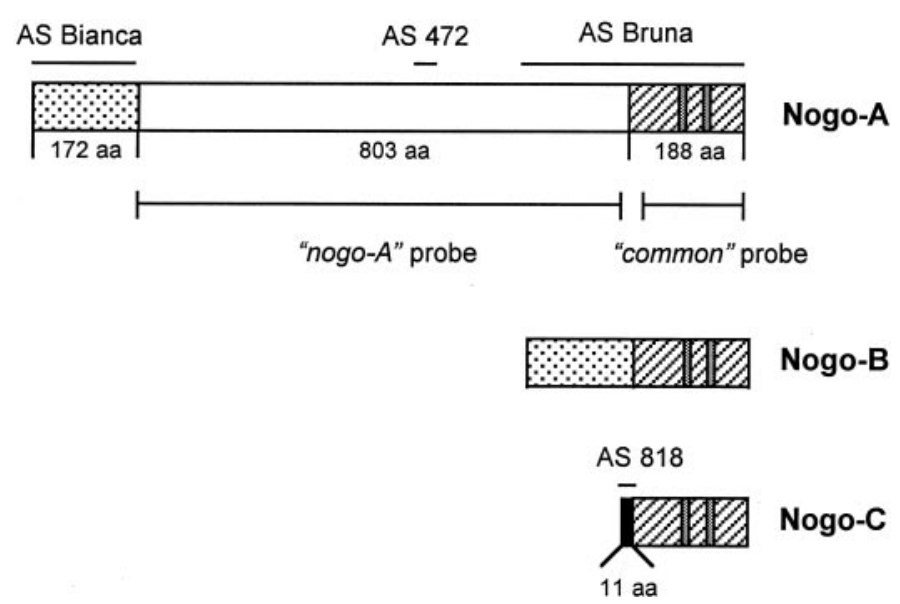

Figure 1. Nogo isoforms, probes, and antisera. The three nogo transcripts with the common region (hatched), Nogo-A-specific region (white), Nogo-A/B-specific N terminus (dotted), and Nogo-C-specific N terminus (black, 11 aa) are shown. Two long hydrophobic stretches (35 and 36 aa) in the region common to all three isoforms, serving as potential transmembrane domains, are marked (gray). Riboprobes used for in situ hybridization and Northern blot are shown: nogo- $A$ and common probes. AS 472 and AS 818 were raised against peptides recognizing Nogo-A and $-\mathrm{C}$, respectively. AS Bianca was raised against the Nogo-A/B-specific N terminus, and AS Bruna was raised against a bacterial recombinant protein including the common part present in all three Nogo isoforms and the C-terminal portion of the Nogo-A-specific region. Note that Nogo-B has no unique sequence.

glutaraldehyde, and $70 \mathrm{mg}$ of $\mathrm{CaCl}_{2}$ in $0.1 \mathrm{M}$ phosphate buffer. Optic nerves were dissected and post-fixed overnight in the same solution. The tissue was washed in $0.1 \mathrm{~m}$ cacodylate buffer, osmicated for $1 \mathrm{hr}$ in $1 \%$ $\mathrm{OsO}_{4}$ in cacodylate buffer, dehydrated through an ascending series of alcohol followed by $10 \mathrm{~min}$ in propylene oxide twice, and then embedded in Epon araldite. After curing, ultrathin sections of 70-90 nm were cut, taken up on nickel grids, and processed for Nogo-A, MAG, and MOG immunoreactivity by overnight incubation at $4^{\circ} \mathrm{C}$ with AS 472 (affinitypurified, diluted 1:20 in blocking buffer containing 10\% goat serum and $2.5 \%$ ovalbumin), anti-MAG (1:2), and anti-MOG (1:2), followed by gold-coupled secondary antibodies (1:50; British Biocell, Cardiff, UK) and staining with uranyl acetate. On some sections, etching by sodium ethoxide $(3 \mathrm{M} \mathrm{NaOH}$ in ethanol diluted 1:300 and incubated for $20 \mathrm{sec})$ was used to expose the antigen and to increase specific labeling (Trapp et al., 1989). The absolute density of the gold label was increased after etching, but the relative density between different compartments was very similar to that of nonetched sections. Control sections stained with either preimmune serum or secondary antibody only did not show significant amounts of gold labeling. The sections were analyzed in a Zeiss EM 902 microscope. Two independent observers, blinded to the experimental conditions, counted the distribution of gold grains in the following compartments: axonal cytoplasm, inner loop of myelin sheath and axon membrane (the two compartments cannot be distinguished), compact myelin, and outer loop of myelin sheath. Gold grains in a $20-30 \mathrm{~nm}$ interface zone that could not be unequivocally assigned to one compartment were counted separately as an overlap compartment and later distributed according to the calculated ratios between the two interfacing compartments. The volume densities of the four compartments were determined stereologically by a point grid and used to calculate a relative density of immunogold labeling for each compartment (Weibel et al., 1966). Approximately 750 fields were counted per animal for four different animals, and a mean relative density of Nogo-A immunoreactivity was calculated.

\section{RESULTS}

The distribution patterns of Nogo mRNAs and proteins during development and in the adult were analyzed using in situ hybridization and immunohistochemistry on rat brain and spinal cord sections between E14 and adult. Several probes and antibodies against different epitopes of the Nogo sequence allowed us to distinguish between the two isoforms Nogo-A and -C (Fig. 1). Because Nogo-B has no unique sequence (Chen et al., 2000), it was only possible to determine its expression by exclusion: a signal observed with AS Bruna, AS Bianca, and the common probe but not with AS 472, the nogo- $A$ probe, or AS 818, specific for Nogo-C, indicated expression of the middle-sized transcript, Nogo-B. We therefore use the term Nogo-A/B when no distinction was possible. Matched preparations using nogo sense probes, preimmune sera, or antisera preincubated with the relevant immunogenic peptide were used as controls; they gave no significant signals in any of the tissues studied. For immunohistochemistry, we used different fixation protocols of the fresh frozen sections: ethanol and acetic acid visualized Nogo expression in myelin, but exposure to this fixative reduced the signal in nonmyelinated tissues (e.g., spinal motor neurons and interneurons in Fig. $4 E, G)$, presumably by extraction of the antigen. Fixation with methanol showed expression of Nogo in cell bodies of oligodendrocytes and neurons (see Fig. $4 F, H$ ), but the myelin staining was weakened. Exposure to EGTA before ethanol and acetic acid fixation allowed visualization of Nogo expressed both in myelin

\begin{tabular}{|c|c|c|c|}
\hline Location & Nogo- $\mathrm{A}^{a}$ & Nogo-A $/ B^{b}$ & Nogo- $\mathrm{C}^{c}$ \\
\hline \multicolumn{4}{|l|}{ Spinal cord } \\
\hline White matter & $+++^{d}$ & $+++^{d}$ & $-^{d}$ \\
\hline Oligodendrocyte cell bodies & $+++^{d, e}$ & $+++^{d, e}$ & $(+)^{e, f}$ \\
\hline Astrocytes & - & - & - \\
\hline Motor neurons & $+^{e}$ & $+^{e}$ & - \\
\hline Interneurons & $+^{e}$ & $+^{e}$ & - \\
\hline \multicolumn{4}{|l|}{ Cerebral cortex } \\
\hline Layer I & $-d, e$ & $-d, e$ & - \\
\hline Layer II/III & $++^{d, e}$ & $++^{d, e}$ & $(+)^{e, f}$ \\
\hline Layer IV & $+^{d, e}$ & $+^{d, e}$ & $(+)^{e, f}$ \\
\hline Layer V/VI & $++^{d, e}$ & $++^{d, e}$ & $(+)^{e, f}$ \\
\hline \multicolumn{4}{|l|}{ Hippocampus } \\
\hline CA1-CA4 & $++^{d, e}$ & $++^{d, e}$ & $(+)^{e, f}$ \\
\hline Dentate gyrus & $+^{d, e}$ & $+^{d, e}$ & $(+)^{e, f}$ \\
\hline Habenula & $+++^{d, e}$ & $+++^{d, e}$ & $(+)^{e, f}$ \\
\hline \multicolumn{4}{|l|}{ Cerebellum } \\
\hline Granule cells & $-g$ & $-g$ & - \\
\hline Purkinje cells & $+d, e$ & $+d, e$ & $++^{e, f}$ \\
\hline Molecular layer & $+^{d, e}$ & $+^{d, e}$ & $++^{e, f}$ \\
\hline Deep cerebellar nuclei & $+++d, e$ & $+++d, e$ & $--^{e, f}$ \\
\hline \multicolumn{4}{|l|}{ Retina } \\
\hline Retinal ganglion cells & $++^{d, e}$ & $++^{d, e}$ & - \\
\hline Inner and outer nuclear layer & $++^{d, e}$ & $++^{d, e}$ & - \\
\hline \multicolumn{4}{|l|}{ Peripheral ganglia } \\
\hline Dorsal root ganglia & $++{ }^{d, e}$ & $++^{d, e}$ & - \\
\hline
\end{tabular}

Semiquantitative analysis of the Nogo expression in the nervous system as found in immunohistochemistry on tissue sections. -, Undetectable; $(+)$, very weak; +, present; ++, strong; +++ , very strong.

${ }^{a}$ AS 472.

${ }^{b}$ AS Bruna or AS Bianca.

${ }^{c}$ AS 818.

${ }^{d}$ Fresh frozen sections post-treated with ethanol and acetic acid or EGTA-ethanol and acetic acid.

${ }^{e}$ Fresh frozen sections post-treated with methanol or methanol-DMSO.

${ }^{f}$ Fresh frozen sections post-treated with $0.1 \%$ paraformaldehyde for immunohistochemical visualization of the three Nogo isoforms in different tissues.

${ }^{g}$ Granule cell layer of the cerebellum shows weak unspecific staining (negative in in situ hybridization and histoblot). 


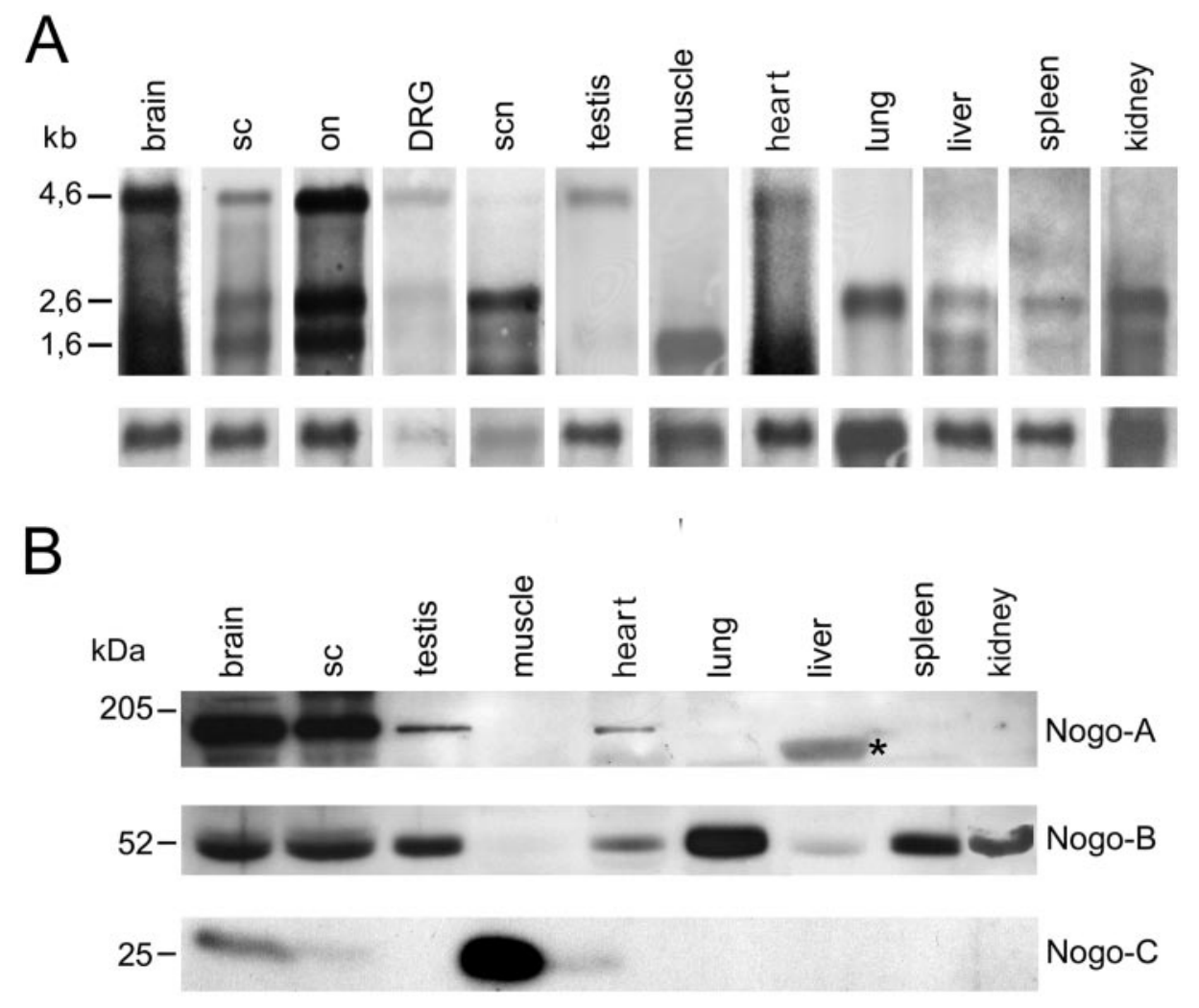

Figure 2. Northern and Western blot analysis. $A$, Northern hybridization with the C-terminal common probe on mRNA of adult rat tissues revealed nogo- $A(4.6 \mathrm{~kb})$ to be strongly expressed in brain, spinal cord (sc), and optic nerve (on). Low levels of nogo- $A$ mRNA were found in DRG, sciatic nerve $(s c n)$, testis, and heart. Note that for DRG and sciatic nerve, less mRNA was loaded than for the other tissues. nogo-B mRNA (2.6 kb) was high in the CNS but was also detected in DRG, sciatic nerve, lung, and kidney and at lower level in testis, liver, and spleen. Strong expression of nogo- $C$ (1.7 kb) was observed in spinal cord, brain, optic nerve, and skeletal muscle. In sciatic nerve, heart, liver, spleen, and kidney, expression was lower. For loading control, the blot was reprobed with a glyceraldehyde-3-phosphate dehydrogenase riboprobe. $B$, In the adult rat, Nogo-A (190 kDa) was strongly expressed in brain and spinal cord, as revealed by AS 472 (and AS Bruna and AS Bianca; data not shown). Apart from the nervous system, Nogo-A was only expressed in detectable amounts in testis and heart. The band present in liver (asterisk) was also detected by preimmune sera and secondary antibody only and represents therefore an unspecific signal. AS Bianca showed expression of Nogo-B (55 kDa) in brain, spinal cord, testis, heart, lung, liver, spleen, and kidney. AS 818 detected a strong Nogo-C band at $25 \mathrm{kDa}$ in skeletal muscle. The smallest Nogo isoform was also present in brain and heart, 40 and $5 \%$, respectively, of the amount present in skeletal muscle, as revealed by densitometric analysis on Western blots with the same amount of total protein loaded.

and in cell bodies; however, the tissue preservation was somewhat impaired compared with the other methods. Table 1 summarizes the expression of the three Nogo isoforms in the adult rat and the use of the different fixatives.

\section{Northern and Western blot analysis}

Northern Blot analysis of adult rat tissues with the common riboprobe revealed that the longest isoform, nogo- $A$, was mainly transcribed in myelinated tissues of the CNS: optic nerve, spinal cord, and brain showed a very prominent band at $4.6 \mathrm{~kb}$ (Fig. 2A). Smaller amounts of nogo- $A$ mRNA could also be detected in dorsal root ganglion (DRG), sciatic nerve, heart, and testis. High nogo- $B$ mRNA (2.6 kb) levels were found in optic nerve, spinal cord, and brain and also in sciatic nerve, lung, and kidney (Fig. $2 A$ ). Lower levels of nogo- $B$ mRNA were found in DRG, testis, spleen, heart, and liver, whereas no nogo- $B$ mRNA was detectable in skeletal muscle. nogo- $C$ mRNA $(1.7 \mathrm{~kb})$ was highly expressed in skeletal muscle, optic nerve, spinal cord, and brain. Lower levels were present in heart, liver, spleen, and kidney.

On Western blots of adult tissue extracts, Nogo-A was present in brain and spinal cord, and low levels were also found in testis and heart (Fig. 2B). None of the other peripheral tissues tested expressed detectable levels of Nogo-A. Nogo-B, revealed by incubation of the Western blot with AS Bianca, was present in brain, spinal cord, testis, heart, lung, spleen, and kidney. Low levels were also found in liver. Skeletal muscle did not express detectable amounts of Nogo-B protein. High levels of Nogo-C were detected with AS 818 in skeletal muscle, whereas a weaker signal was found in brain, spinal cord, and heart.

\section{In situ hybridization and immunohistochemistry}

During development, expression of Nogo-C protein, the smallest of the three Nogos, was prominent in peripheral tissues such as skeletal muscle, skin, and intestinal epithelium, whereas expression in the nervous system was undetectable with the currently available antisera (Fig. 3E,F). However, Nogo-C was present in postnatal Purkinje cells (see Fig. 7), but only very low protein levels were detected in other parts of the CNS (e.g., cortex; see Fig. 5I).

\section{Spinal cord and peripheral ganglia}

Nogo-A/B was expressed at the earliest time point analyzed, E14, in neurons of the spinal cord with the highest level in ventral 


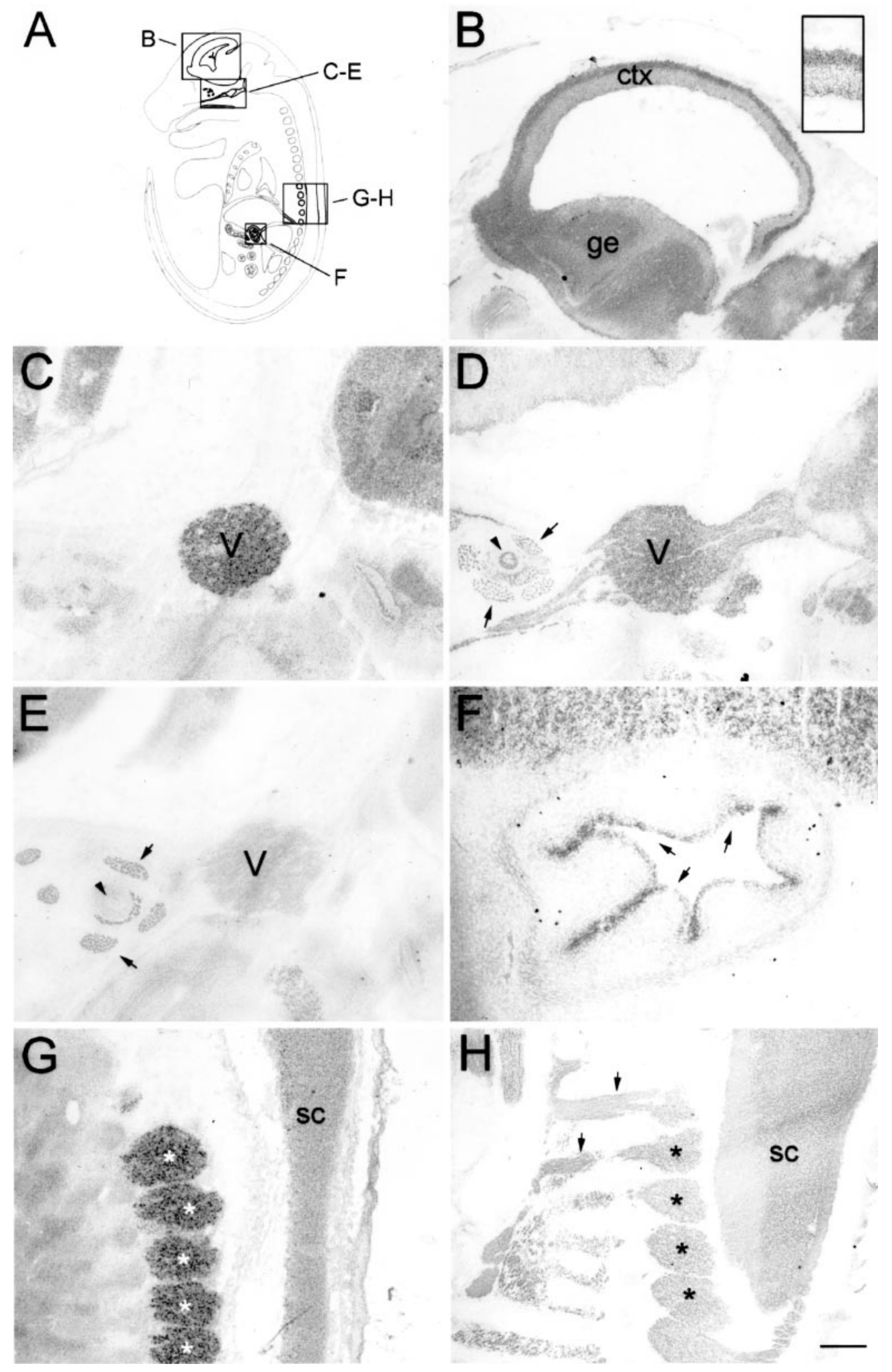

Figure 3. Nogo expression in the E16 rat embryo. In situ hybridization with the nogo- $A$ probe revealed strong expression in the mantle layer of postmitotic neurons in the developing forebrain cortex $(B$, inset $)$. In the trigeminal ganglion $(C, D ; V)$, high levels of Nogo-A were detected $(C$, nogo- $A$ probe; $D$, AS 472). Nogo-A protein was also found in the trigeminal nerve fibers, extraocular muscles (arrows), and optic nerve (arrowhead). Note that Nogo-C (AS 818; E) was only present in extraocular muscles (arrows) but not in the trigeminal ganglion or optic nerve. Strong expression of Nogo-C was found with AS 818 in intestinal epithelium $(F$, arrows). $G, H$, Nogo-A mRNA $(G)$ and protein $(H)$ expression in the spinal cord (sc) and DRG (asterisks). Again, protein expression revealed by AS 472 was also found in nerve fibers $(H, a r-$ rows), whereas mRNA expression (nogo- $A$ probe) was restricted to neuronal cell bodies in the DRG and spinal cord. The level of mRNA expression in DRG was higher than in the spinal cord; however, protein levels were comparable. Scale bar: $B-E, G, H, 550 \mu \mathrm{m} ; F, B$, inset, $140 \mu \mathrm{m}$. motor neurons. Peripheral ganglia such as DRG and sympathetic ganglia were also expressing Nogo-A/B (Fig. 4A,B). In P3 and P5 animals, large neurons in intermediate laminae around the central canal were strongly expressing Nogo, in addition to the ventral motor neurons. At ages later than P5, a slight downregulation of AS 472 immunoreactivity particularly in more caudal motor neurons was observed, whereas the signal with the corre- sponding nogo- $A$ RNA probe remained strong (data not shown). This effect was less pronounced with AS Bruna and AS Bianca, possibly reflecting a differential expression of Nogo-A and -B. Interneurons on all levels of the spinal cord showed strong expression of nogo mRNA in the adult, comparable with the intensity of motor neurons, whereas Nogo protein expression was low (Fig. 4C,E). Fixation with ethanol and acetic acid resulted in a 

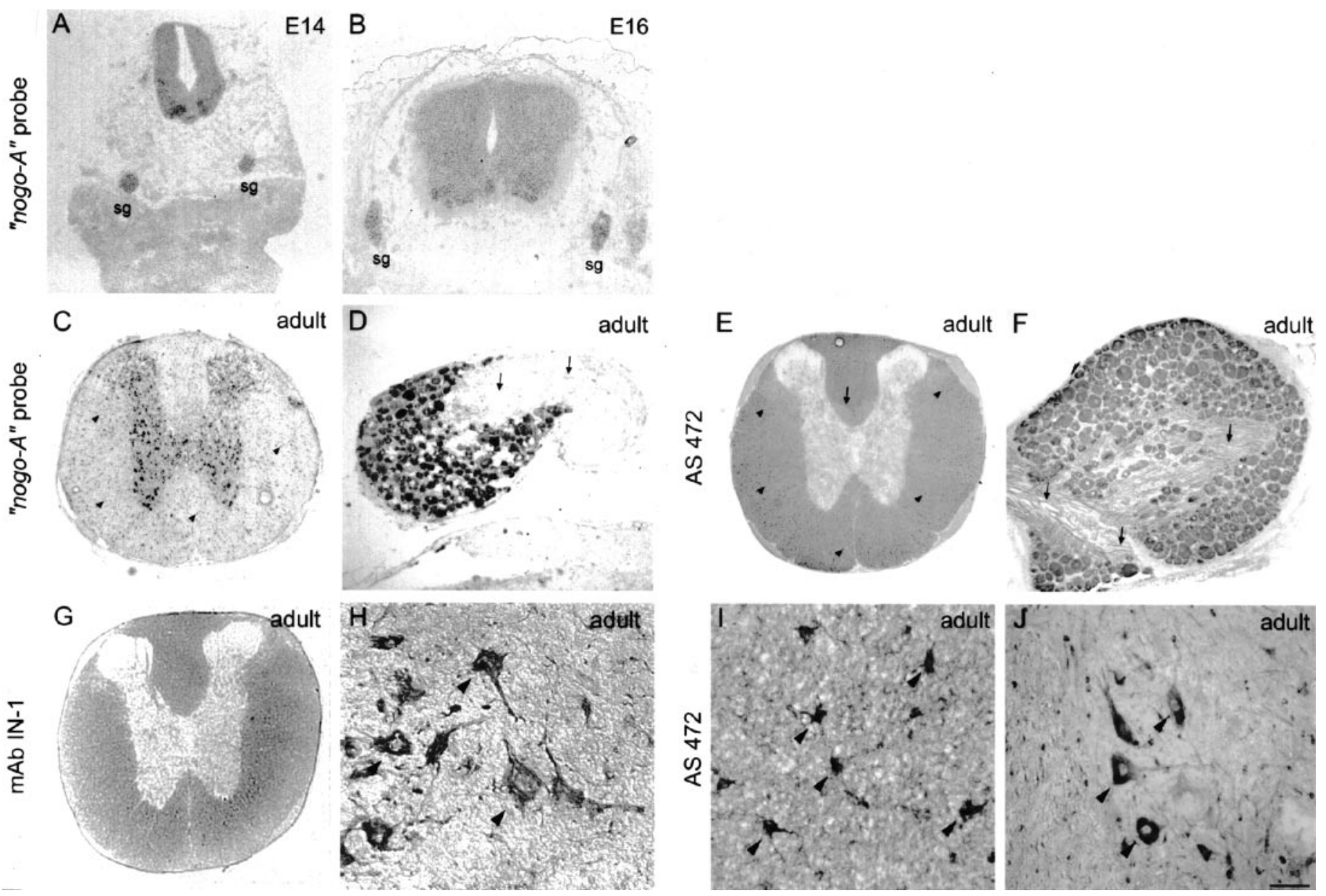

Figure 4. Nogo-A expression in the spinal cord and dorsal root ganglia. In situ hybridization with the nogo- $A$ probe showed the presence of this transcript in neuronal subtypes of the spinal cord, DRG, and sympathetic ganglia $(\mathrm{sg})$ at E14 $(A)$ and E16 $(B)$. In the adult, nogo- $A$ mRNA was found in oligodendrocyte cell bodies in the white matter $(C$, arrowheads). The corresponding immunohistochemistry with AS $472(E, I)$ revealed Nogo-A expression mainly in the myelinated areas of the spinal cord and very intensely in oligodendrocyte cell bodies $(E$, $I$, arrowheads). Less strongly myelinated areas such as the region of the corticospinal tract $(E$, arrow) were also stained less. Fixation of the tissue with ethanol and acetic acid $(A, B, E, G, I)$ revealed the Nogo-A localized to myelin and oligodendrocyte cell bodies. Neuronal Nogo-A was visualized by fixation with methanol $(F, H, J)$. Spinal neurons in the gray matter were expressing nogo- $A$ mRNA $(C)$ and Nogo-A protein ( $H$, high magnification of motor neurons). Strong Nogo-A expression was found in adult DRG neurons and their neurites $(F$, arrows), whereas the neurites were not stained with the nogo- $A$ probe $(D$, arrows $)$. mAb IN-1 strongly stained white matter and oligodendrocyte cell bodies $(G)$ as well as motor neurons (methanol fixation; $H$ ). Scale bar: $A, C, E$, $G, 460 \mu$ m; $B$, $275 \mu \mathrm{m} ; D, F, H-J, 140 \mu \mathrm{m}$.

strong Nogo signal in myelin, whereas the neuronal Nogo was extracted to a large degree by this method; therefore, the neuronal signal is very weak (Fig. 4E,G). However, expression of Nogo-A in motor neurons was observed in sections fixed with methanol by AS 472 (Fig. 4J) very similar to staining patterns obtained by mAb IN-1 (Fig. 4H). Postnatally, the strongest Nogo-A protein expression was found in myelin and oligodendrocyte cell bodies, as revealed with AS 472 (Fig. 4E,I) and mAb IN-1 (Fig. 4G).

DRGs were stained with both the AS 472/nogo- $A$ probe and AS Bruna/common probe from the earliest time point observed, E14, until the adult stage (Figs. $3 G, H, 4 D, F$ ). Although Nogo-A protein was detected in peripheral nerve, no mRNA was found, pointing to an axonal location and lack of Nogo-A expression in Schwann cells and perineurium (Fig. 4D,F, arrows). Nogo-A/B was also detected at high levels in peripheral ganglia other than DRG, e.g., the trigeminal ganglion (Fig. 3C,D).

\section{Neocortex and hippocampus}

At no developmental stage analyzed was any differential mRNA expression (common vs nogo-A probe) or difference in staining with AS Bruna and AS Bianca or AS 472 detected. It is therefore not possible to make a statement about specific expression of Nogo-B, and we are referring to Nogo-A/B. Nogo-C was not detectable with AS 818 during development, and only very low expression was found in the cortex in the adult (Fig. 5I). In E16 animals, postmitotic neurons in the mantle layer were strongly expressing Nogo-A/B, whereas the matrix layer, comprising the dividing cells, was stained less intensely (Fig. 3B, inset). Three days later, neurons in the cortical plate, mantle layer, and matrix layer were expressing Nogo-A/B. Large subplate neurons were Nogo-A/B-positive at E19-P5 (Fig. 5A-D). Nogo-A/B was found in neurons of the cortical plate and additionally in the subplate neurons. At P3, when the neocortex already consisted of several layers, neurons in layer IV were primarily negative, whereas 


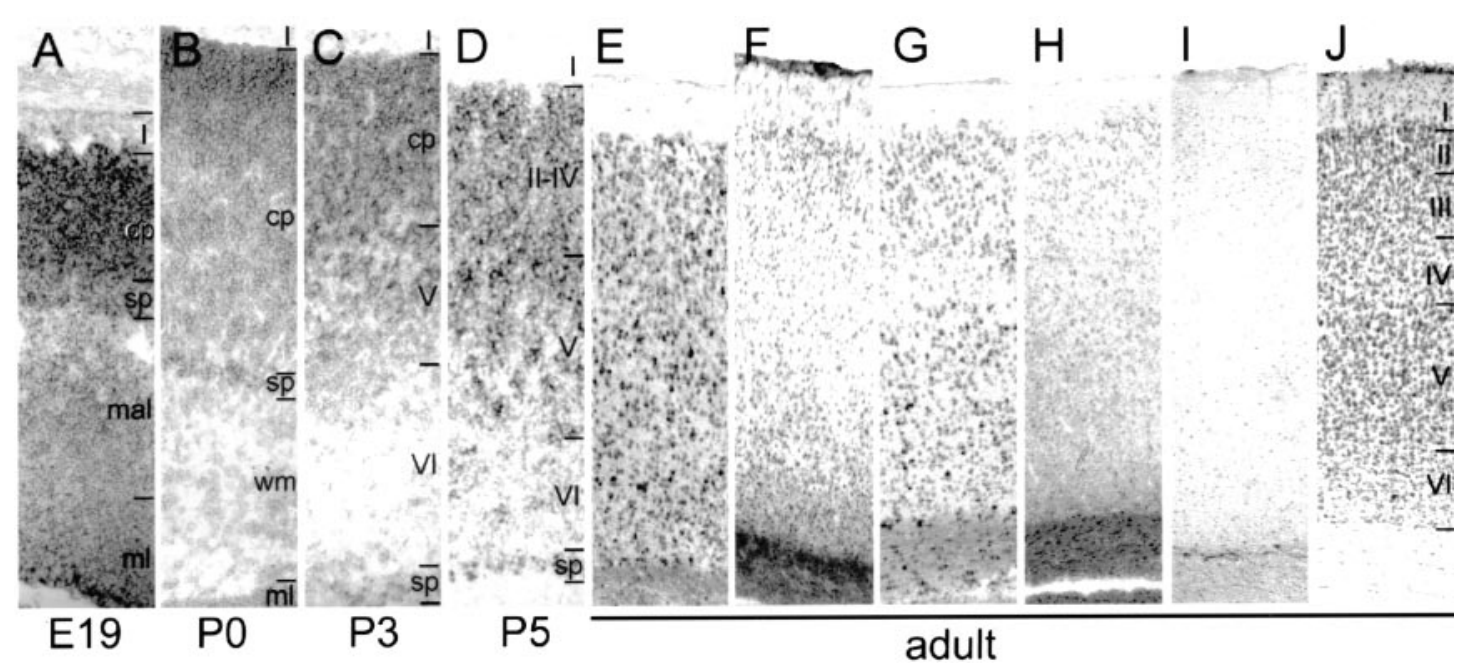

Figure 5. Nogo-A, -B, and -C expression in the neocortex. $A-E$, In situ hybridizations with the common probe. $F$, AS Bruna; $G$, "nogo- $A$ " probe; $H$, AS 472; I, AS 818; $J$, Nissl staining. In E19 $(A)$, a strong nogo- $A / B$ signal was observed in the matrix layer $(m l)$, mantle layer (mal), and cortical plate $(c p)$. Also at birth $(B)$, strong expression in cortical plate and subplate was found, which was persisting in P3 $(C)$ and P5 $(D)$. Neurons in layer V were strongly expressing nogo- $A / B$ in P3, whereas layer VI was only weakly stained. In the adult $(E-J)$, neurons in layer IV of the cortex were stained weaker for Nogo-A/B than neurons in layers II and III and V and VI. Very low levels of Nogo-C protein were detected with AS 818 (I). Image width: $A-D$, 210 $\mu \mathrm{m} ; E-J, 420 \mu \mathrm{m}$.

neurons in layer $\mathrm{V}$ and in the cortical plate were expressing Nogo-A/B. All neurons migrated to their layers at P5, where Nogo was found to be expressed in some cells of layer VI, but more neurons were positive in layers II-IV and V. In adult animals, in situ hybridization with both probes revealed mRNA signals in neurons of all cortical layers with lower levels in layer IV neurons (Fig. 5, E, common probe, $G$, nogo- $A$ probe), whereas the level of protein expression seemed relatively low compared with oligodendrocyte cell bodies in the corpus callosum (Fig. 5, F, AS Bruna, $H$, AS 472).

In the hippocampus, strong expression of Nogo-A was observed in the regions CA1-CA4 by both in situ hybridization and immunohistochemistry at birth (Fig. 6A,B). The granule cells of the dentate gyrus expressed less Nogo-A mRNA and protein. In the adult, expression of Nogo-A and -B was seen in the pyramidal cells of CA1-CA4, whereas less signal could be detected in the dentate gyrus (Fig. $6 C-F$ ). In addition to the stratum pyramidale, Nogo-A was also detected in hippocampal fiber layers by immunohistochemistry (Fig. 6F) and histoblotting (Fig. 6K). Overall, the protein expression in neurons was low, however, compared with the white matter of the fimbria-fornix and the corpus callosum. Interestingly, parvalbumin- and calbindin-positive hippocampal interneurons were also found to express Nogo-A (Fig. $6, G, H, I, J$, respectively).

\section{Cerebellum}

In the cerebellum, differential expression of Nogo-A, -B, and -C was observed. Purkinje cells were expressing Nogo-A/B from birth on, as revealed by AS Bruna, AS Bianca, and AS 472 and corresponding RNA probes (Fig. 7). Nogo-C, however, was only found at low levels in Purkinje cells at P3 (Fig. 7E), but expression increased during postnatal development (Fig. 7J,O). In addition to high levels in the soma, the Nogo proteins were also found in Purkinje cell dendrites (Fig. 7N,O, insets). The external granular layer (EGL) showed mRNA expression of nogo- $A / B$ at P3, which started to decrease from P5 on and was nearly undetectable at P14 (Fig. $7 A, C, F, H$ ). Interestingly, the strongest immunoreactivity at
P0-P9 was found in the premigratory zone of the EGL, whereas the outermost sublayer, the proliferative zone, was stained less (Altman, 1972a) (Fig. 7C, inset). Once the granule cells had migrated past the Purkinje cells to their final position in the granule cell layer, none of the Nogo isoforms was expressed in these cells anymore.

Consistent with the appearance of differentiated and myelinating oligodendrocytes (Reynolds and Wilkins, 1988), Nogo-Apositive small, non-neuronal cells were first detected at P5 in the region of the deep cerebellar nuclei. With time they extended toward the end of the folia (P9) and could also be detected in the granule cell layer from P14 on (Fig. $7 F-J$ ). Nogo-A protein was highest in white matter from P14 to adult. Neurons in the deep cerebellar nuclei expressed Nogo-A/B protein at birth and throughout development, with very high levels present in the adult (Fig. 7).

\section{Retina}

Nogo-A/B mRNA and protein were found in all neuronal cell types of the retina from embryonic ages on. At birth, Nogo-A/B was expressed in retinal ganglion cells as well as in the cytoblast layer giving rise to the inner and outer nuclear layer (Fig. 8B,C).

Immunoreactivity for AS 472 and AS Bruna and hybridization signals for the common and nogo- $A$ probes were equally strong at all time points observed (data not shown), therefore prohibiting any statement about specific expression of Nogo-B. Nogo-A, Nogo-A/B mRNA and protein expression, or both, in retinal ganglion cells was strong in the adult (Fig. 8E,F). Nogo-A and Nogo-A/B proteins seem to be targeted to neurites, because the inner and outer plexiform layers were stained with AS Bruna, whereas no in situ hybridization signal was detected in these structures.

\section{Subcellular localization of Nogo-A in white matter}

Confocal microscopic analysis of sections of adult rat spinal cord and optic nerve revealed that Nogo-A was mainly found in 

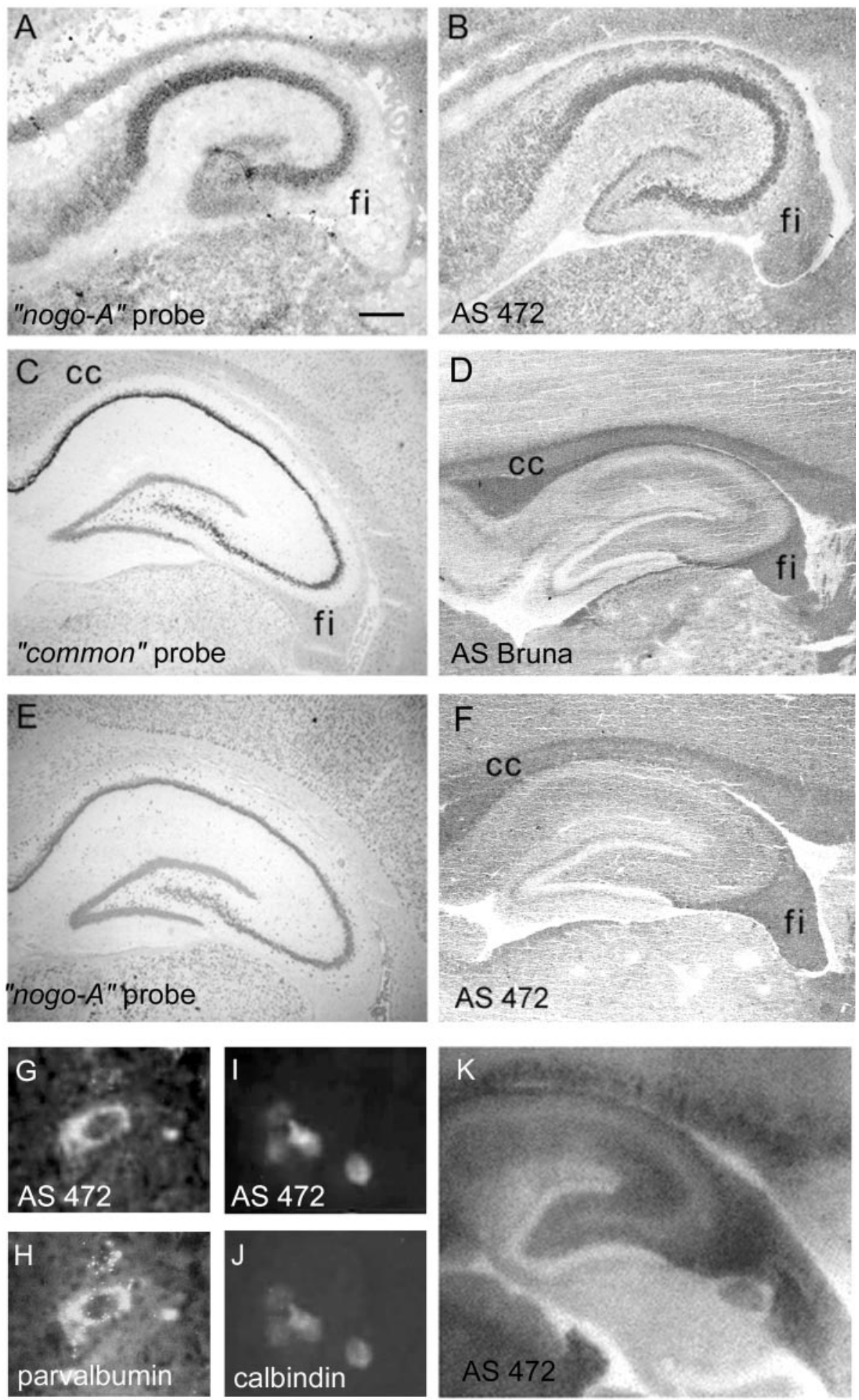

oligodendrocyte cell bodies and processes as well as in the outermost (outer loop) and innermost, adaxonal (inner loop) myelin membrane (Fig. 9). Colocalization with MBP was minor, showing that Nogo-A is not detectably expressed in the compact myelin (Fig. 9A,B). Nogo-A did colocalize with MAG, known to be localized specifically in the innermost loop of the myelin membrane (Trapp et al., 1989) (Fig. 9G-I), and MOG, localized in the outermost loop of the myelin sheath (Fig. 9E). Double immunohistochemistry with an antibody against the astrocyte marker glial fibrillary acidic protein (GFAP) did not result in any colocalization, demonstrating that Nogo-A is not present in astrocytes (Fig. $9 F$ ).

Postembedding immunoelectron microscopy of adult rat optic nerves confirmed these observations (Fig. 10). The highest immunoreactivity for Nogo-A was found in an area that comprised the innermost loop of the myelin sheath and the axonal membrane. Lower but specific labeling was present over the outer myelin loop, and only very low labeling was present over compact 
P3
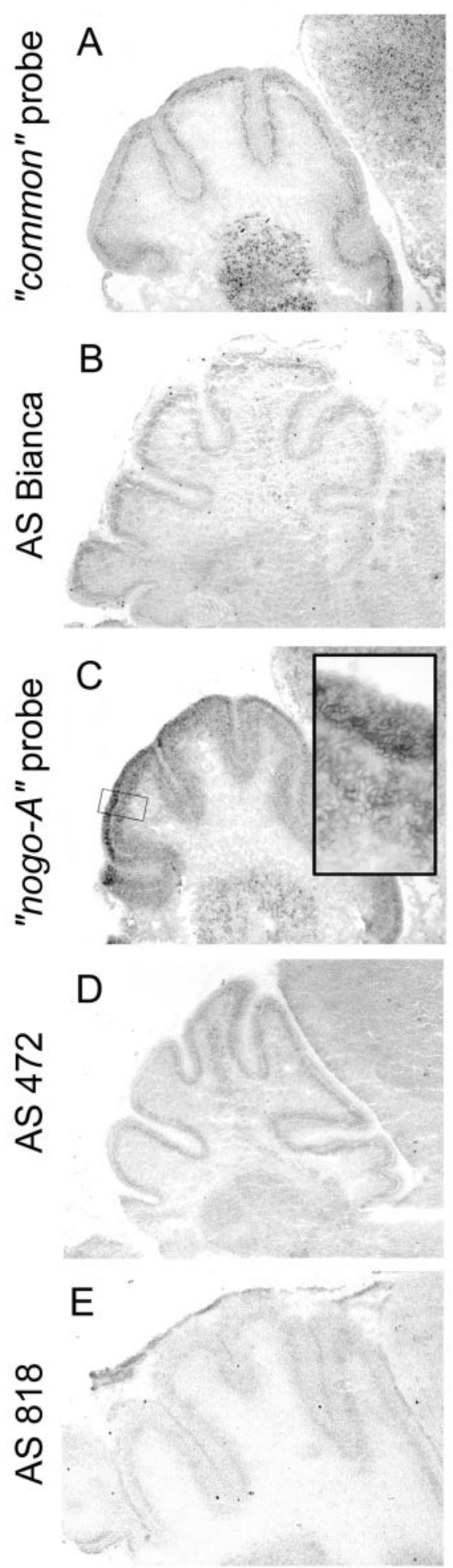

P14
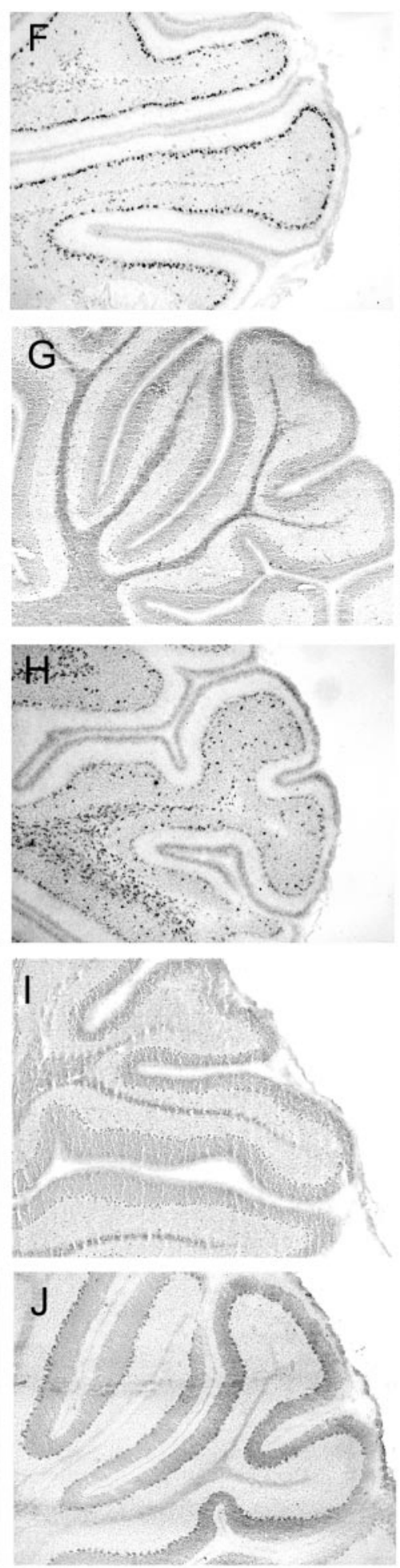

adult
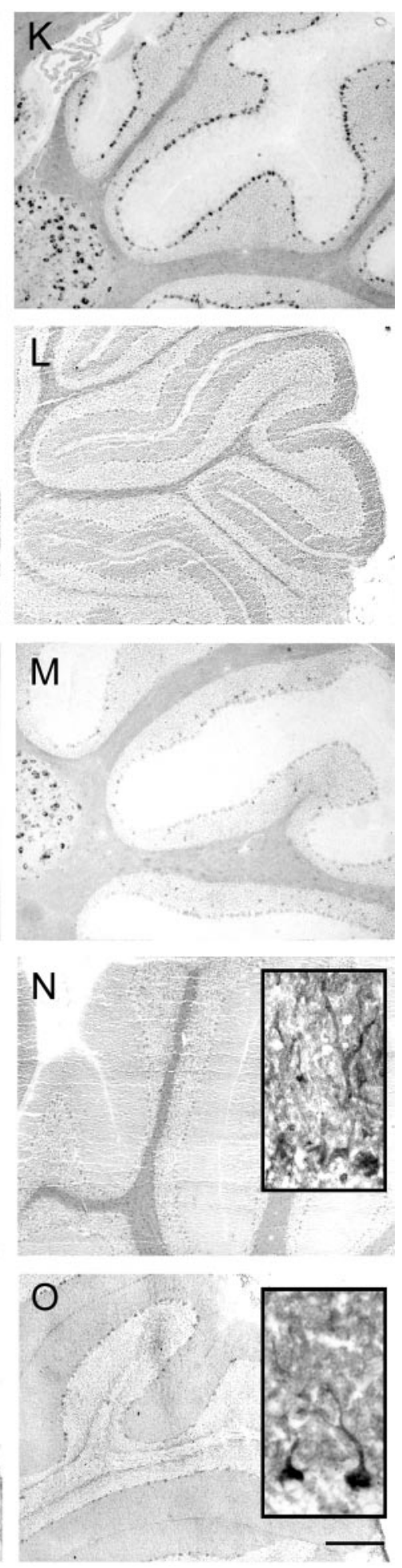

Figure 7. Nogo expression in the cerebellum. At $\mathrm{P} 3(A-E)$, Nogo-A/B was expressed in Purkinje cells $(A$, common probe; $B$, AS Bianca; $C$, nogo- $A$ probe; $D$, AS 472), whereas very little Nogo-C was found in these neurons ( $E$, AS 818 ). Nogo-C revealed by immunohistochemistry with AS 818 was found in Purkinje cells in P14 and adult $(J, O)$. Nogo-A-positive neurons in the premigratory layer of the EGL were more strongly stained than the outermost, proliferative sublayer $(C$, inset $)$. Nogo-A/B expression remained high in oligodendrocytes in the white matter and in oligodendrocytes in the granule cell layer in P14 and adult. Neurons in the deep cerebellar nuclei were strongly expressing Nogo-A/B at all time points. Sections stained with AS Bianca $(B, G, L)$ and AS $472(D, I, N)$ were fixed with EGTA-ethanol and acetic acid, revealing the prominent expression of Nogo-A/B in white matter, Purkinje cells, and their dendrites. Scale bar: $275 \mu \mathrm{m}$; insets, $35 \mu \mathrm{m}$. 
Figure 8. Nogo expression in the retina.
At birth $(A-C)$, strong expression of Nogo-A/B mRNA ( $B$, common probe) and protein $(C$, AS Bruna) in the ganglion cell layer $(\mathrm{gcl})$ as well as the cytoblast layer $(c b)$ was observed. Expression was highest at the interface between the ganglion cell layer and cytoblast layer. The ganglion cells were also Nogo-A/Bpositive in the adult $(D-F)$, and both inner and outer nuclear layers (inl, onl) were expressing mRNA (E, common probe) and protein ( $F$, AS Bruna). Nogo$\mathrm{A} / \mathrm{B}$ protein seemed to be targeted to neurites, because the inner and outer plexiform layers ( $\mathrm{ipl}, \mathrm{opl}$ ) were positive for AS Bruna $(F)$. A, $D$, Nissl staining. Scale bar, $70 \mu \mathrm{m}$.
Nissl
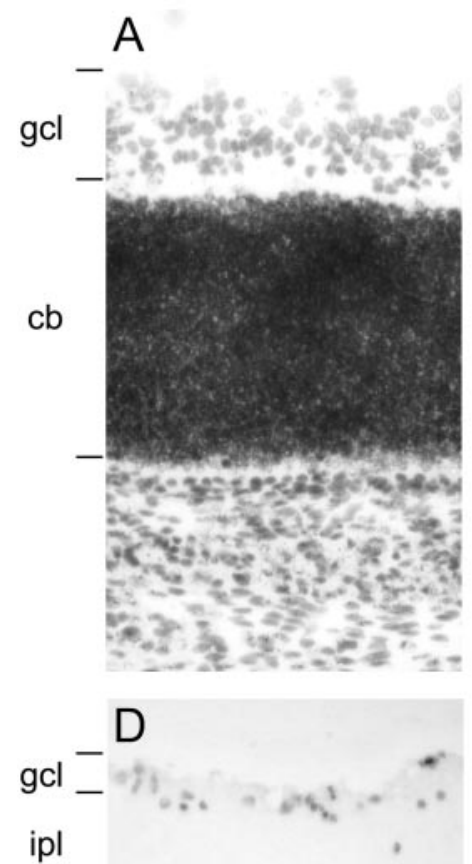

"common" probe
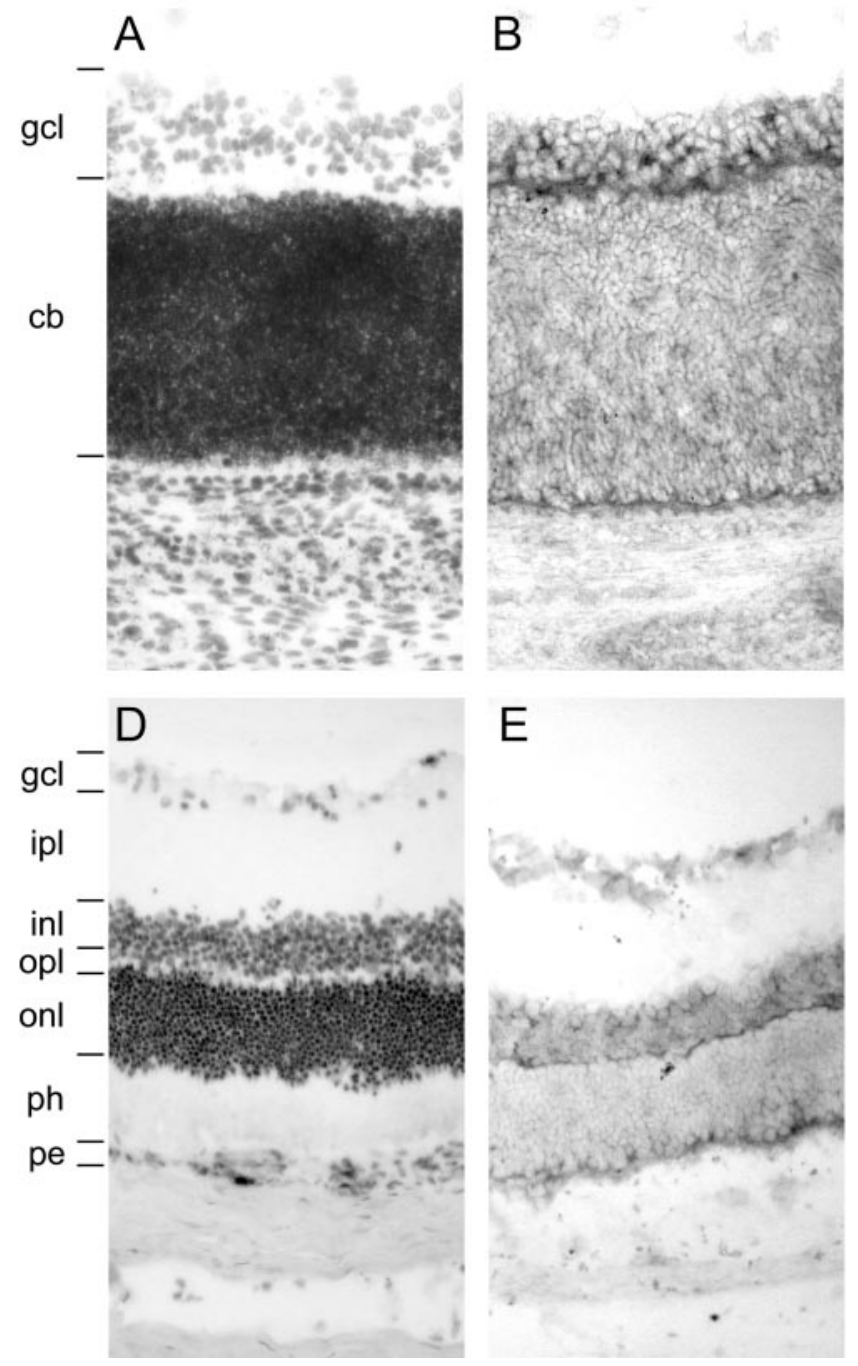

AS Bruna

C

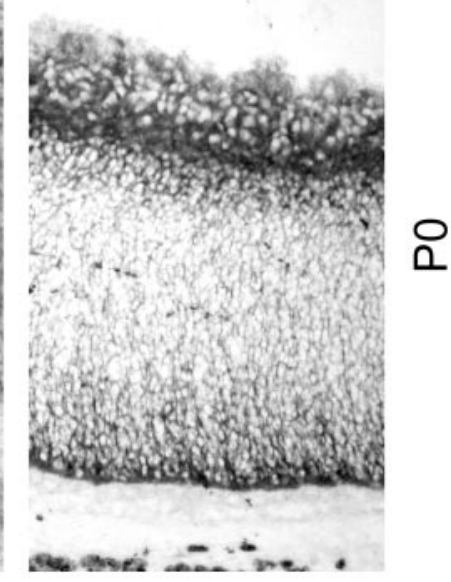

$\mathrm{F}$

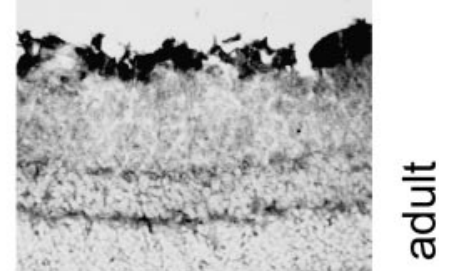

myelin and the axonal cytoplasm. The relative density for Nogo-A in the inner loop was $8.8 \pm 0.12$ (SEM) times higher than in compact myelin. In the outer loop, the relative Nogo-A immunoreactivity was $4.0 \pm 0.12$ times higher than in compact myelin (Fig. 10).

Confocal microscopic analysis revealed colocalization of Nogo-A with neurofilament in axons (Fig. 9C,D). Immunoelectron microscopy demonstrated only a $1.2 \pm 0.21$ times higher relative Nogo-A density in the axoplasm than in compact myelin (Fig. 10D). Because axonal and inner loop membranes are close together, the resolution of the immunogold technique does not allow clear distinction between them. However, when optic nerve sections very close to the eyeball where axons are not myelinated were stained with AS 472 and analyzed by electron microscopy, no significant labeling was found. This suggests that the bulk of Nogo-A is indeed expressed in the innermost loop of the myelin sheath and not or only at low levels in the axonal membrane (data not shown).

\section{Nogo expression after CNS lesions}

Nogo-A has initially been identified as a myelin-associated neurite growth inhibitor involved in regenerative failure after injury. Therefore, its expression after CNS lesions is particularly inter- esting. We studied expression of Nogo-A/B after both cortical and spinal lesions after $1,4,7,14$, and $28 \mathrm{~d}$. At all time points studied, no obvious changes in expression of nogo- $A / B$ transcripts were found in oligodendrocytes. Nonaffected tissue in the vicinity of the lesion continued to express Nogo-A/B at normal levels in both white and gray matter (Fig. 11). With time, the lesion area was filled with infiltrating cells, and a glial scar developed. Neither infiltrating cells nor scar-forming astrocytes and fibroblasts expressed Nogo-A/B mRNA or protein at detectable levels (Fig. 11). We therefore conclude that inhibition of fiber regeneration by Nogo-A is exerted by the intact tissue adjacent to CNS lesion sites rather than by increased expression at the site of injury. At $4 \mathrm{~d}$ after lesion, slight upregulation of Nogo-A/B mRNA and protein expression was observed in cortical neurons in the vicinity of the injury but not in spinal cord and at any other time point (Fig. 11 $A, B$ ).

\section{DISCUSSION}

We have investigated the expression pattern of the three Nogo isoforms, Nogo- $\mathrm{A},-\mathrm{B}$, and $-\mathrm{C}$, in the developing and adult rat nervous system. Nogo-A was present in oligodendrocytes and the innermost and outermost myelin membrane, consistent with its function as a myelin-associated neurite growth inhibitor. In ad- 

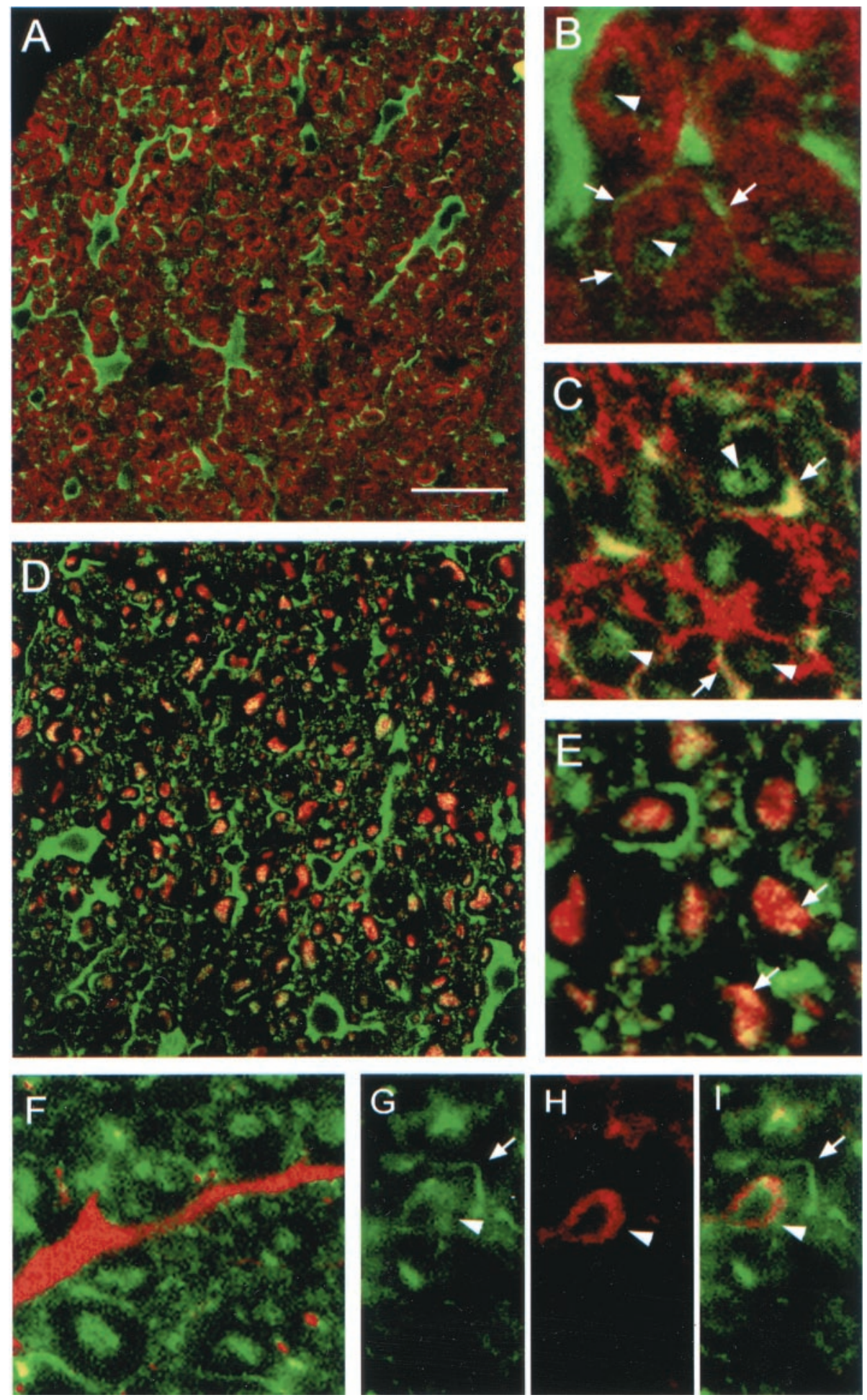

Figure 9. Localization of Nogo-A in CNS white matter by confocal microscopic analysis. $A$, No colocalization of Nogo-A (shown by AS 472 in green) was found with MBP (red), which is a major constituent of compact myelin. Nogo-A was expressed in oligodendrocyte cell bodies, their processes, and the inner loop ( $B, C$, arrowheads) and outer loop $(B, C$, arrows) of the myelin sheath. The fixation protocol required to demonstrate MBP expression lowered the Nogo-A signal in the inner loop of the myelin membrane, whereas the different protocol used for MAG and MOG immunohistochemistry showed strong expression of Nogo-A in the inner and outer loops of the myelin sheath. E, Nogo-A (AS 472, green) is expressed in the outer loop (arrows) of the myelin sheath and was found to colocalize there with MOG (red). G, A strong Nogo-A signal (AS 472, green) was also found in the inner loop (arrowheads), where MAG $(H, r e d)$ is expressed. $C, D$, Some Nogo-A (AS 472, green) was also present in axons, as was demonstrated by colocalization ( yellow) of AS 472 with an antibody against neurofilament (red). F, Nogo-A (AS 472, green) was not present in astrocyte processes stained by an antibody against GFAP (red). Scale bar: $A, C, 85 \mu \mathrm{m}$; $B, D-I, 45 \mu \mathrm{m}$. dition, Nogo-A, Nogo-B, or both as well as Nogo-C were found in the developing and adult nervous system, in particular in several types of neurons. This wide expression pattern, including early developmental stages, suggests additional functions for the Nogo proteins. In a recent paper (Josephson et al., 2001), similar results were reported for Nogo-A/B mRNA expression in spinal cord and in peripheral neurons. However, protein expression of the Nogo isoforms and subcellular localization were not addressed in that study.

\section{Nogo-A in oligodendrocytes and myelin}

Nogo-A was found in oligodendrocyte cell bodies and white matter of the adult CNS. Confocal analysis revealed no colocalization with MBP in compact myelin but showed the presence of Nogo-A in the inner loop of the myelin sheath, in the outer myelin loop, and in oligodendrocyte cell bodies and processes. Immunoelectron microscopy confirmed these observations: Nogo-A immunoreactivity was high in the inner and outer loops of the myelin sheath and low in the compact myelin. 

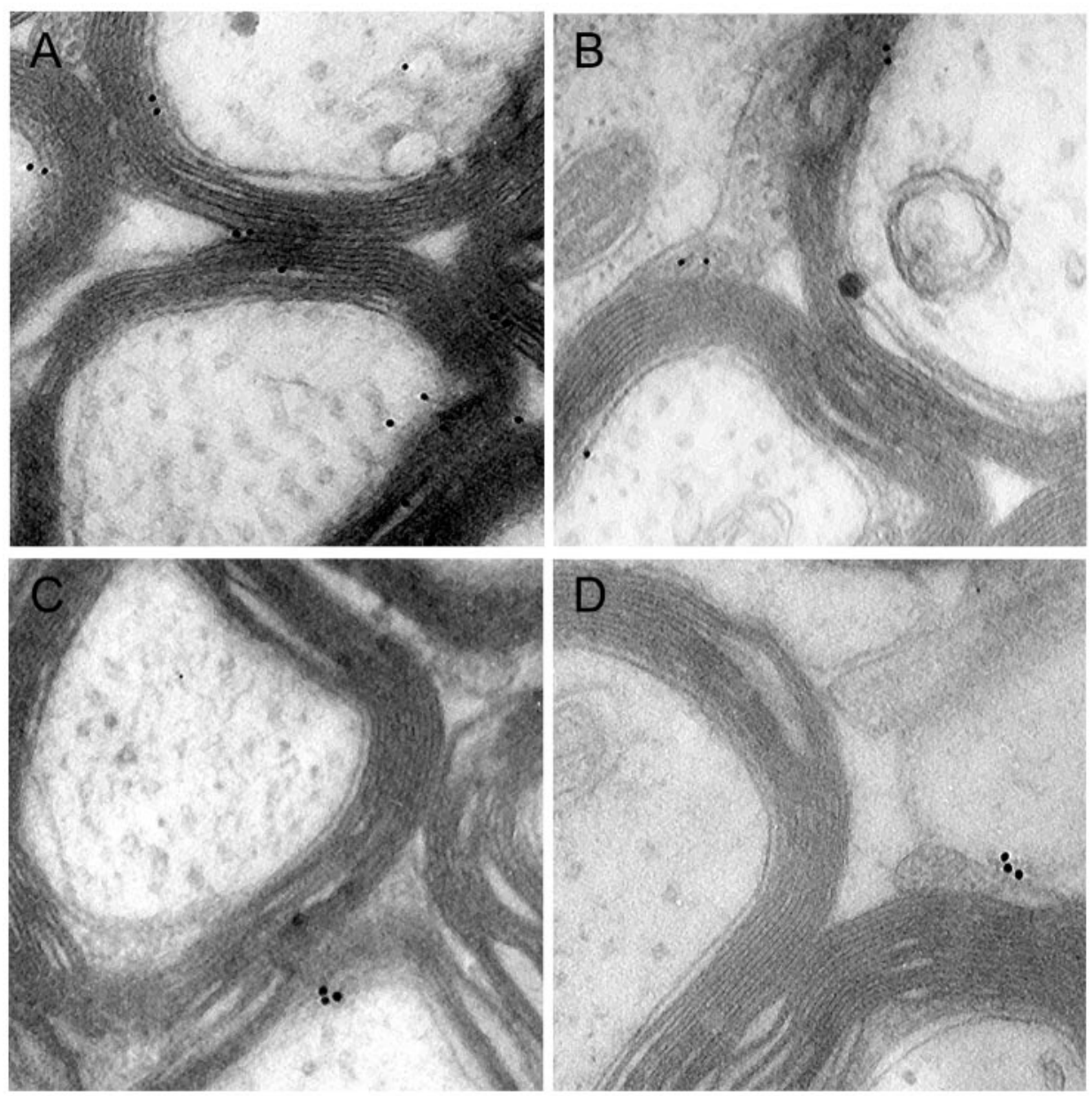

Figure 10. Localization of Nogo-A in the optic nerve by immunoelectron microscopy. Nogo-A was detected on optic nerve ultrathin sections by immunogold electron microscopy. $A, B$, AS 472 gold grains (arrows) were found at the inner loop and less frequently at the outer loop of the myelin sheath. Expression of MAG $(C$, arrowhead $)$ was detected in the innermost loop, and MOG ( $D$, arrowhead) immunoreactivity was detected in the outer loop. E, Double labeling for Nogo-A (small grains; arrows) and MAG (large grains; arrowheads) confirmed this distribution. $F$, Quantification and statistical analysis of the distribution of Nogo-A protein in adult rat optic nerve. Scale bar: $A-D, 0.25 \mu \mathrm{m} ; E$, $0.5 \mu \mathrm{m}$.
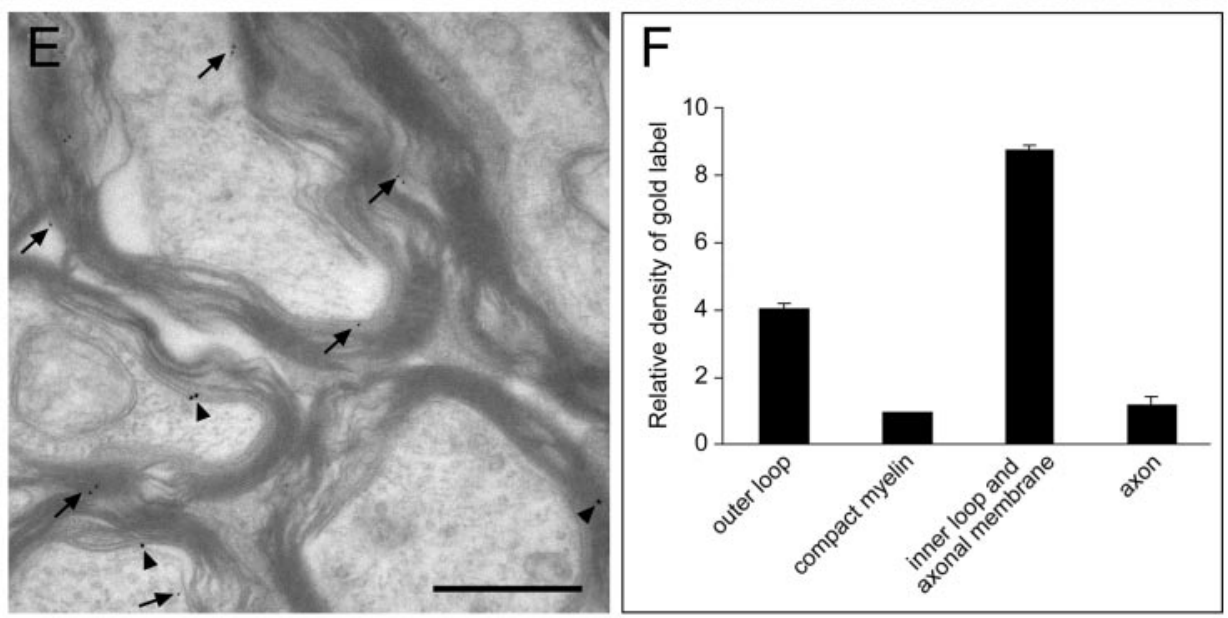

In the developing cerebellum, appearance of Nogo-A in oligodendrocytes coincided with myelination: $\operatorname{nog} O-A$ mRNA in the oligodendrocytes of the developing cerebellum was first detected at P5 in the deep cerebellar regions, and Nogo-A protein was strongly expressed at P9 in oligodendrocytes of the white matter. At P9, Nogo-A-positive cell bodies were found toward the ends of the folia in the white matter, and some labeled cells were found in the granule cell layer. Comparing the appearance of Nogo-A with the time course of expression of the major myelin protein MBP, it became apparent that Nogo-A is just preceding MBP expression and myelination (Reynolds and Wilkins, 1988).
Nogo-A has been cloned as a myelin-associated inhibitor of regenerative axon growth. We have studied Nogo-A expression levels at several time points after brain and spinal cord lesions and found no evidence for decreased or increased expression in oligodendrocytes, unlike MBP and proteolipid protein, which are upregulated after injury (Bartholdi and Schwab, 1998; Frei et al., 2000). Also, we did not find detectable expression of Nogo-A in the scar tissue in and around the lesion site, as was described for other repulsive molecules, e.g., Sema3A in fibroblast-like cells (Pasterkamp et al., 1999) or proteoglycans in astrocytes (Levine, 1994; McKeon et al., 1995). Rather than being a lesion-induced 


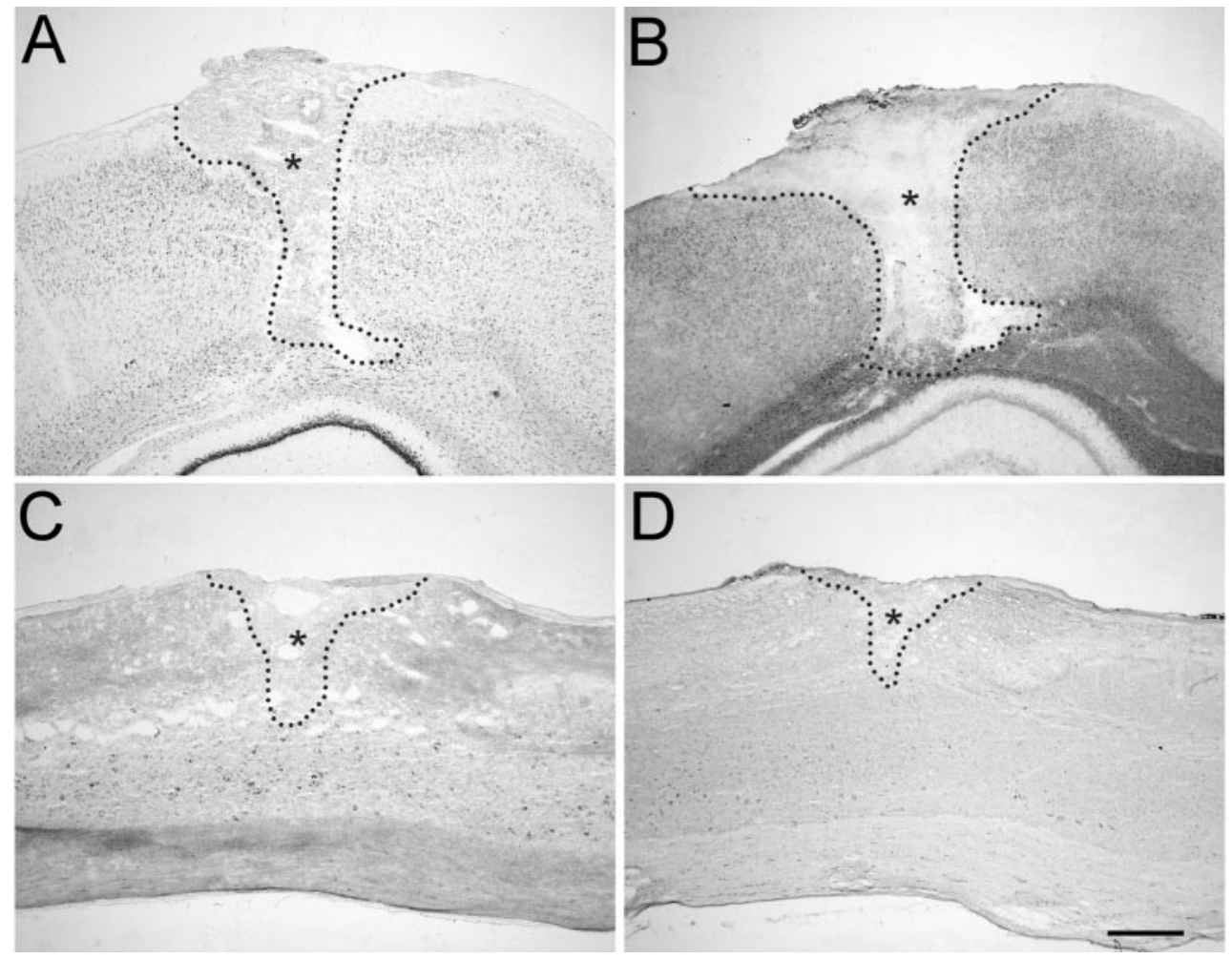

Figure 11. Expression of Nogo mRNA and protein is unchanged after traumatic CNS injury. $A$, In situ hybridization with common Nogo probe $4 \mathrm{~d}$ after cortical lesion. $B$, Corresponding immunohistochemistry (AS Bruna) on an adjacent section. A slight upregulation of Nogo-A/B in cortical neurons in the vicinity of the injury was observed at this time point but not at any other time point or in spinal cord. Note the Nogo-free lesion area and lesion borders. $C$, In situ hybridization with the common probe. $D$, Immunohistochemistry with AS Bruna 4 weeks after spinal lesion. No detectable upregulation or downregulation can be observed. The lesion areas are outlined and marked by asterisks. Scale bar, $550 \mu \mathrm{m}$. factor, Nogo-A therefore likely restricts fiber growth in the intact tissue in the vicinity of the lesion and farther away, where it is normally expressed in oligodendrocytes. This is consistent with recent experiments that pointed toward tonic inhibition of an internal growth program in the neuron by Nogo-A: after application of Nogo-A-neutralizing antibodies to the intact adult rat cerebellum, profuse sprouting of uninjured Purkinje cell axons and upregulation of growth-associated genes were observed (Zagrebelsky et al., 1998; Buffo et al., 2000). Dissociated DRG neurons transplanted into myelinated fiber tracts have been shown to be able to grow long axonal processes (Davies et al., 1997). It is unclear how these cells, which are clearly responsive to Nogo-A in culture (Chen et al., 2000), can overcome this inhibition in vivo. Because lesioned dorsal roots normally do not regenerate into the spinal cord, altered sensitivity of these transplanted, ectopic neurons to growth inhibitors appears likely, possibly through altered receptor or second messenger levels (Cai et al., 1999; Fournier et al., 2001).

\section{Nogo expression in neurons}

Nogo-A mRNA and protein was expressed in neuronal cell bodies and neurites as early as E14. No function of the neuronal Nogo-A is known; however, it seems unlikely that the neurite growth inhibition is mediated by Nogo-A expressed in neurons. Extensive functional studies in vitro revealed consistent effects of the neutralizing antibody IN-1 on the substrate only; myelin preparations or living, cultured oligodendrocyte substrates were preincubated with IN-1 and washed, and neurons were subsequently added (Caroni et al., 1988). Culture of DRG neurons in the presence of IN-1 on a laminin substrate had no effect on neurite growth (A. B. Huber and M. E. Schwab, unpublished observations). In oligodendrocytes, only a small portion of Nogo-A is transported to the cell surface, whereas the majority is associated with endoplasmic reticulum (ER) and Golgi (van der
Haar et al., 2001). It remains to be determined whether neurons are expressing any Nogo isoform at the cell surface. Depending on subcellular localization, several possibilities of a neuronal function of Nogo-A are conceivable: (1) Nogo-A could act as a cell surface signal, repulsive, attractive, or other, for other neurons, neurites, or non-neuronal cells. Different receptors or downstream pathways may mediate the specificity of action, as has been shown, e.g., for netrin-1 (Hong et al., 1999). Strikingly, we found Nogo-A to be highly expressed in the premigratory zone of the EGL in the developing cerebellum. Cerebellar granule cells are generated in the proliferative zone of the EGL starting around $\mathrm{P} 0$, accumulate in the premigratory layer, and then migrate inward past the Purkinje cells to form the granule cell layer (Altman, 1972a,b). The granule cells of the internal granule cell layer were not expressing Nogo-A anymore, indicating possible involvement of Nogo-A in granule cell migration. That molecules involved in axon guidance can also influence neuronal migration has been shown recently, e.g., for netrin-1 (Blelloch et al., 1999; Yee et al., 1999; Alcantara et al., 2000), semaphorins (Hu and Rutishauser, 1996; Eickholt et al., 1999), and Slit (Wu et al., 1999). Nogo-A may thus be another example of a multifunctional signal molecule such as members of the neurotrophin family, which have been shown to be involved in such diverse functions as neurite outgrowth, cell survival or death decisions, and synaptic plasticity (Casaccia-Bonnefil et al., 1999; Klintsova and Greenough, 1999; Davies, 2000). (2) Although signal-transducing motifs on Nogo-A have not yet been found, a function of Nogo-A or Nogo-B as a receptor for an as yet unknown ligand is well conceivable. Bidirectional signaling is known for another family of, in part, repulsive molecules, the ephrins and Eph receptors (Klein, 1999). (3) Nogo-A, -B, and -C could also have an intracellular function in neurons, possibly in addition to the neurite growth-inhibitory activity on the cell surface of oligodendrocytes. 
Intracellularly, Nogo-A is expressed in a reticular pattern (GrandPré et al., 2000; A. B. Huber, M. E. van der Haar, M. E. Schwab, unpublished observations), as are Nogo-B and $-\mathrm{C}$ and other members of the reticulon family of proteins (van de Velde et al., 1994). The function of the reticulons, to which Nogo-A, -B, and $-\mathrm{C}$ are related in the common, $\mathrm{C}$-terminal domain, is unknown. Roles in protein transfer through the ER, protein packaging, trafficking, or both, and regulation of intracellular calcium levels have been suggested (van de Velde et al., 1994). The two shorter Nogo forms have a widespread expression pattern, including peripheral tissues. To date, the physiological functions of Nogo-B and -C are unknown. In addition to the potent inhibitory activity found in the Nogo-A-specific part of the molecule (Oertle et al., 2000; Prinjha et al., 2000), membranes of Nogo-A- and Nogo-C-transfected human embryonic kidney cells and a 66residue region in the $\mathrm{C}$-terminal domain of Nogo expressed as glutathione $S$-transferase fusion proteins in bacteria were able to induce DRG growth cone collapse in vitro (GrandPré et al., 2000). Recently, a neuron-specific receptor for this 66-residue portion of Nogo was identified (Fournier et al., 2001). Recombinant Nogo-C did not inhibit axon outgrowth in vitro (Oertle et al., 2000), but it remains to be demonstrated whether Nogo-B and -C get transported to the cell surface and expose their 66-residue loop between the two transmembrane domains, as has been shown for Nogo-A (GrandPré et al., 2000).

In conclusion, our results demonstrate that Nogo-A is localized in CNS myelin in a way that is consistent with its described function as a neurite growth inhibitor. At the same time, the expression of Nogo-A during development, in particular in neurons, and the widespread expression of its isoforms Nogo-B and -C suggest additional, yet unknown functions of this protein.

\section{REFERENCES}

Alcantara S, Ruiz M, De Castro F, Soriano E, Sotelo C (2000) Netrin-1 acts as an attractive of repulsive cue for distinct migration neurons during the development of the cerebellar system. Development 127:1359-1372.

Altman J (1972a) Postnatal development of the cerebellar cortex in the rat. I. The external germinal layer and the transitional molecular layer. J Comp Neurol 145:353-397.

Altman J (1972b) Postnatal development of the cerebellar cortex in the rat. III. Maturation of the components of the granular layer. J Comp Neurol 145:465-513.

Bartholdi D, Schwab ME (1998) Oligodendroglial reaction following spinal cord injury in rat: transient upregulation of MBP mRNA. Glia 23:278-284.

Benke D, Wenzel A, Scheuer L, Fritschy JM, Mohler H (1995) Immunobiological characterization of the NMDA-receptor subunit NR1 in the developing and adult rat brain. J Recept Signal Transduct Res 15:393-411.

Blelloch R, Newman C, Kimble J (1999) Control of cell migration during Caenorhabditis elegans development. Curr Opin Cell Biol 11:608-613.

Bregman BS, Kunkel-Bagden E, Schnell L, Dai HN, Gao D, Schwab ME (1995) Recovery from spinal cord injury mediated by antibodies to neurite growth inhibitors. Nature 378:498-501.

Brösamle C, Huber AB, Fiedler M, Skerra A, Schwab ME (2000) Regeneration of lesioned corticospinal tract fibers in the adult rat induced by a recombinant, humanized $\mathrm{IN}-1$ antibody fragment. J Neurosci 20:8061-8068.

Buffo A, Zagrebelsky M, Huber AB, Skerra A, Schwab ME, Strata P, Rossi F (2000) Application of neutralizing antibodies against NI-35/ 250 myelin-associated neurite outgrowth inhibitory proteins to the adult rat cerebellum induces sprouting of uninjured Purkinje cell axons. J Neurosci 20:2275-2286.

Cai D, Shen Y, De Bellard M, Tang S, Filbin MT (1999) Prior exposure to neurotrophins blocks inhibition of axonal regeneration by MAG and myelin via a cAMP-dependent mechanism. Neuron 22:89-101.

Caroni P, Schwab ME (1988) Antibody against myelin-associated inhibitor of neurite growth neutralizes nonpermissive substrate properties of CNS white matter. Neuron 1:85-96.

Caroni P, Savio T, Schwab ME (1988) Central nervous system regener- ation: oligodendrocytes and myelin as non-permissive substrates for neurite growth. Prog Brain Res 78:363-369.

Casaccia-Bonnefil P, Gu C, Chao MV (1999) Neurotrophins in cell survival/death decisions. Adv Exp Med Biol 468:275-282.

Chen MS, Huber AB, van der Haar ME, Frank M, Schnell L, Spillmann AA, Christ F, Schwab ME (2000) Nogo-A is a myelin-associated neurite outgrowth inhibitor and an antigen for monoclonal antibody IN-1. Nature 403:434-439.

Davies AM (2000) Neurotrophins: neurotrophic modulation of neurite growth. Curr Biol 10:R198-R200.

Davies SJ, Fitch MT, Memberg SP, Hall AK, Raisman G, Silver J (1997) Regeneration of adult axons in white matter tracts of the central nervous system. Nature 390:680-683.

Eickholt BJ, Mackenzie SL, Graham A, Walsh FS, Doherty P (1999) Evidence for collapsin-1 functioning in the control of neural crest migration in both trunk and hindbrain regions. Development 126:2181-2189.

Fournier AE, GrandPré T, Strittmatter SM (2001) Identification of a receptor mediating Nogo-66 inhibition of axonal regeneration. Nature 409:341-346.

Frank M, van der Haar ME, Schaeren-Wiemers N, Schwab ME (1998) rMal is a glycosphingolipid-associated protein of myelin and apical membranes of epithelial cells in kidney and stomach. J Neurosci 18:4901-4913.

Frei E, Klusman I, Schnell L, Schwab ME (2000) Reactions of oligodendrocytes to spinal cord injury: cell survival and myelin repair. Exp Neurol 163:373-380.

GrandPré T, Nakamura F, Vartanian T, Strittmatter SM (2000) Identification of the Nogo inhibitor of axon regeneration as a reticulon protein. Nature 403:439-444.

Hong K, Hinck L, Nishiyama M, Poo MM, Tessier-Lavinge M, Stein E (1999) A ligand-gated association between cytoplasmic domains of UNC5 and DCC family receptors converts netrin-induced growth cone attraction to repulsion. Cell 97:927-941.

$\mathrm{Hu} \mathrm{H}$, Rutishauser U (1996) A septum-derived chemorepulsive factor for migrating olfactory interneuron precursors. Neuron 16:933-940.

Josephson A, Widenfalk J, Widmer HW, Olson L, Spenger C (2001) Nogo mRNA expression in adult and fetal human and rat nervous tissue and in weight drop injury. Exp Neurol 169:319-328.

Klein R (1999) Bidirectional signals establish boundaries. Curr Biol 9:R691-R694.

Klintsova AY, Greenough WT (1999) Synaptic plasticity in cortical systems. Curr Opin Neurobiol 9:203-208.

Levine JM (1994) Increased expression of the NG2 chondroitin-sulfate proteoglycan after brain injury. J Neurosci 14:4716-4730.

McKeon RJ, Hoke A, Silver J (1995) Injury-induced proteoglycans inhibit the potential for laminin-mediated axon growth on astrocytic scars. Exp Neurol 136:32-43.

Oertle T, Bandtlow CE, Schwab ME (2000) Characterization of the gene structure and the inhibitory regions of Nogo/RTN4. Soc Neurosci Abstr 26:573.

Olson L (1997) Regeneration in the adult central nervous system: experimental repair strategies. Nat Med 3:1329-1335.

Pasterkamp RJ, Giger RJ, Ruitenberg MJ, Holtmaat AJ, De Wit J, De Winter F, Verhaagen J (1999) Expression of the gene encoding the chemorepellent semaphorin III is induced in the fibroblast component of neural scar tissue formed following injuries of adult but not neonatal CNS. Mol Cell Neurosci 13:143-166.

Prinjha R, Moore SE, Christie G, Michalovich D, Simmons DL, Walsh FS (2000) Inhibitor of neurite outgrowth in humans. Nature 403:383-384.

Reynolds R, Wilkins GP (1988) Development of macroglial cell in rat cerebellum. II. An in situ immunohistochemical study of oligodendroglial lineage from precursor to mature myelinating cell. Development 102:409-425

Rubin BP, Dusart I, Schwab ME (1994) A monoclonal antibody (IN-1) which neutralizes neurite growth inhibitory proteins in the rat CNS recognizes antigens localized in CNS myelin. J Neurocytol 23:209-217.

Savio T, Schwab ME (1989) Rat CNS white matter, but not gray matter, is nonpermissive for neuronal cell adhesion and fiber outgrowth. J Neurosci 9:1126-1133.

Schaeren-Wiemers N, Gerfin-Moser A (1993) A single protocol to detect transcripts of various types and expression levels in neural tissue and cultured cells: in situ hybridization using digoxigenin-labelled cRNA probes. Histochemistry 100:431-440.

Schnell L, Schwab ME (1990) Axonal regeneration in the rat spinal cord produced by an antibody against myelin-associated neurite growth inhibitors. Nature 343:269-272.

Schwab ME, Bartholdi D (1996) Degeneration and regeneration of axons in the lesioned spinal cord. Physiol Rev 76:319-370.

Spillmann AA, Bandtlow CE, Lottspeich F, Keller F, Schwab ME (1998) Identification and characterization of a bovine neurite growth inhibitor (bNI-220). J Biol Chem 273:19283-19293.

Thallmair M, Metz GAS, Z'Graggen WJ, Raineteau O, Kartje GL, Schwab ME (1998) Neurite growth inhibitors restrict structural plas- 
ticity and functional recovery following corticospinal tract lesions. Nat Neurosci 1:124-131.

Trapp BD, Andrews SB, Cootauco C, Quarles R (1989) The myelinassociated glycoprotein is enriched in multivesicular bodies and periaxonal membranes of actively myelinating oligodendrocytes. J Cell Biol 109:2417-2426.

van der Haar ME, Simonen M, Huber AB, Schnell L, Schwab ME (2001) Localization and membrane topology of the myelin protein Nogo-A. Soc Neurosci Abstr 27:258.10.

van de Velde HJ, Roebroek AJ, Senden NH, Ramaekers FC, Van de Ven WJ (1994) NSP-encoded reticulons, neuroendocrine proteins of a novel gene family associated with membranes of the endoplasmic reticulum. J Cell Sci 107:2403-2416.

Weibel ER, Kistler GS, Scherle WF (1966) Practical stereological methods for morphometric cytology. J Cell Biol 30:23-38.
Wu W, Wong K, Chen J, Jiang Z, Dupuis S, Wu JY, Rao Y (1999) Directional guidance of neuronal migration on the olfactory system by the protein slit. Nature 400:331-336.

Yee KT, Simon HH, Tessier-Lavigne M, O'Leary DDM (1999) Extension of long leading processes and neuronal migration in the mammalian brain directed by the chemoattractant netrin-1. Neuron 24:607-622.

Zagrebelsky M, Buffo A, Skerra A, Schwab ME, Strata P, Rossi F (1998) Retrograde regulation of growth-associated gene expression in adult rat Purkinje cells by myelin-associated neurite growth inhibitory proteins. J Neurosci 18:7912-7929.

Z'Graggen WJ, Metz GAS, Kartje GL, Thallmair M, Schwab ME (1998) Functional recovery and enhanced corticofugal plasticity after unilateral pyramidal tract lesion and blockade of myelin-associated neurite growth inhibitors in the adult rat. J Neurosci 18:4744-4745. 